\title{
Inflation and Unit Labor Cost
}

January 2012

(Revised July 22, 2012)

\author{
Robert G. King \\ Department of Economics, Boston University \\ and
}

Mark W. Watson*

Department of Economics and Woodrow Wilson School, Princeton University

\begin{abstract}
We study two decompositions of inflation, $\pi$, motivated by the standard New Keynesian Pricing Equation of Gali, Gertler, and Sbordone. The first uses four components: lagged $\pi$, expected future $\pi$, real unit labor cost $(\psi)$, and a residual. The second uses two components: fundamental inflation (discounted expected future $\psi$ ) and a residual. We find large lowfrequency differences between actual and fundamental inflation. From 1999-2011 fundamental inflation fell by more than 15 percentage points, while actual inflation changed little. We discuss this discrepancy in terms of the data (a large drop in labor's share of income) and through the lens of a canonical structural model (Smets-Wouters (2007)).
\end{abstract}

*We thank Jordi Gali, Pok-sang Lam, Michael Siemer, two referees, and participants at the Study Center Gerzensee $25^{\text {th }}$ anniversary conference for comments on an earlier draft. Data and replication files for this research can be found at http://www.princeton.edu/ mwatson. 


\section{Introduction}

A notable development of early 21 st century macroeconomics was the rise of dynamic stochastic general equilibrium models at central banks around the world. Constructed along New Keynesian lines, these DSGE models have been increasingly employed as central banks

placed greater weight on inflation targeting frameworks for monetary policy, at times explicitly as in Canada and New Zealand and at times implicitly as in the U.S. and Europe. A price equation stressing unit labor cost, modernizing specifications developed along the lines of Eckstein and Fromm (1968) for an earlier generation of quantitative models, plays a central role in the transmission of shocks from the real sector to inflation in these models. In addition, rational price-setter expectations of unit labor cost also play a key role in the models' inflation dynamics.

This paper provides a transparent accounting of the sources of inflation within the canonical modern macroeconomic policy model, circa 2007, using leading examples of such New Keynesian DSGE modeling. Most modern macroeconomic models feature a structural equation designed along the lines of Gali and Gertler (1999) and Sbordone (2002) that link inflation to fluctuations in expected inflation and real unit labor cost (equivalently, labor's share), which we term the New Keynesian Pricing Equation (NKPE). Notably, a particular NKPE specification is a component of the seven-variable DSGE model that Smets and Wouters (2007) developed for the United States, which we take as our reference DSGE model.

The NKPE specifications that we use are of the "hybrid" form common to Gali and Gertler (1999) and Smets and Wouters (2007), in that they contain an inflation lag as well as expected future inflation. They differ in the values and interpretation of the NKPE coefficients in ways that we discuss further below, but are otherwise similar. Both feature a link to a measure of real marginal cost, with Smets and Wouters (2007) making a model-based correction to standard real unit labor cost. To focus attention on the interaction of the unit labor cost data and the models, we do not estimate any structural parameters in our work, but simply use alternative values estimated by Gali and Gertler (1999) and Smets and Wouters (2007).

Much of our analysis focuses on the 1960-1999 sample period because this (roughly) coincides with the sample period used by Gali and Gertler, Sbordone, and others, and because it was the behavior of inflation over this period which motivates much of this work. After 
reviewing the main features of the behavior of inflation and the theory of the NKPE, we make four contributions. The first two involve the accounting focus discussed above.

First, we develop and use a four-way decomposition of the hybrid NKPE to break inflation into inflation expectations, inflation inertia, cost, and residual. We show that inflation over 1960-1999 is dominated by the inflation expectations component and that real unit labor cost accounts for only a small part. This first finding is common to the NKPE, when we use the parameter estimates of Gali and Gertler (1999) and those of Smets and Wouters (2007). This decomposition highlights how the NKPE is a double-edged sword for an inflation targeting central bank: the dominance of inflation expectations in inflation shows how important it is to manage these, but the small contribution of real unit labor cost shows that direct management is difficult with temporary changes in aggregate demand.

Second, we employ a two-way decomposition based on solving out the NKPE to divide inflation into real cost and residual components, with each being the evolution of an expected present discounted value. Following Gali and Gertler (1999) and Sbordone (2002) who studied similar constructions, we use the label "fundamental inflation" for the marginal cost component. When we implement this decomposition using a bivariate inflation-real unit labor cost VAR to forecast future values of real unit labor cost, we find (like these prior authors) that fundamental inflation comoves strongly with actual inflation. The fundamental inflation decomposition shows that, despite a modest short-run influence of cost, an inflation-targeting central bank could control inflation substantially by having systematic policies to control real activity which smoothed the behavior of real unit labor cost. When we apply our two-way decomposition to the Smets and Wouters (2007) version of the hybrid NKPE using their full general equilibrium model for forecasting marginal cost, we find that fundamental inflation behaves very differently from actual inflation. This decomposition suggests that inflation control would be more problematic, as inflation appears dominated by shocks to the NKPE within the Smets and Wouters (2007) model. More generally, the link between inflation and costs appears very different from an accounting perspective, using the two closely related NKPE frameworks.

Third, we undertake detective work aimed at solving this inflation-cost puzzle. Specifically, we consider how differences in the NKPE parameter values, forecasting methods, and real unit labor costs measures alter the behavior of fundamental inflation. 
Fourth, we explore how this inflation-cost puzzle manifests itself in the structural interpretation of inflation dynamics within the Smets and Wouters DSGE model. Specifically we highlight how the structure of their model implies that inflation must be explained primarily by the model's price shocks and also that these shocks must have opposite effects on inflation and marginal cost. Simply put, an important part of inflation in the model arises from exogenous price shocks that drive up inflation and drive down labor cost. But the inflation generated by these shocks is fairly temporary given the monetary policy rule, while the price markup shocks and the labor cost responses are highly persistent and move in opposite directions. We describe why this negative comovement is an inevitable part of basic "first generation" sticky price DSGE models driven by highly persistent markup shocks and find it interesting that it also appears in the much more elaborate Smets and Wouters model.

We then look forward from the end of the basic data interval in 1999 to examine the inflation cost puzzle in more recent times, finding that it intensifies, and then look back to consider how the evolving behavior of unit labor costs undermines a key motivation for the NKPE.

When we extend the sample through 2010, the real unit labor cost series used by Gali, Gertler, and Sbordone -- as well as the measure used by Smets and Wouters -- exhibit large trend declines at the end of the sample. This leads to a collapse in fundamental inflation on the order of 15 percentage points in the 2000s, a period in which actual inflation is essentially unchanged.

Stepping back, we recall that the NKPE focus on cost measures was developed partly to avoid challenges raised by the modeling of capacity output for empirical analysis of price dynamics: unit labor cost could potentially be unaffected by real trends, while output would not be. ${ }^{1}$ Ironically, it seems that the marginal cost approach now faces the same issues of identifying the effects of trends and productivity shocks that were a major reason for modern pricing analysis to move away from output gaps. Our findings highlight the fact that

\footnotetext{
${ }^{1}$ Fuhrer (1997) argues that the NKPE fails badly when a conventional output gap is employed. However, a class of modern macroeconomic models - those that add nominal frictions to a real business cycle core framework - imply a time-varying level of capacity output due to changes in productivity and other real factors that would make conventional output gaps a poor proxy for pricing pressures, while a measure of real marginal cost (or average markup) would be an appropriate indicator (see, for example, Goodfriend and King (1997)). Gali and Gertler (1999) make an explicit empirical comparison between marginal cost and output gap models of inflation dynamics.
} 
conventional unit labor cost measure is no longer a useful construction for inflation dynamics and has not been at least since the early 2000s.

The organization of the paper is as follows. In section 2, we briefly review the inflation dynamics developed by Gali and Gertler (1999) and Sbordone (2002), which focuses on the comovement of inflation and real unit labor cost. In section 3, we describe the two accounting decompositions discussed above for inflation. In section 4, we consider the implications of the NKPE using the parameter values and forecasting mechanisms previously developed in Gali and Gertler (1999) and then we do the same for the Smets and Wouters (2007) framework. This isolates the inflation-cost puzzle discussed above: a SW fundamental inflation measure is very different from both actual inflation and a GG fundamental inflation measure. ${ }^{2}$ In section 5, we conduct our detective work and solve the puzzle, at least in a mechanical empirical sense, and then we describe how it is manifested in the structural impulse response of the Smets and Wouters DSGE model. In section 6, we briefly look at inflation and labor cost over the longer 1960-2011 interval. We document that a GG fundamental inflation measure displays the same aberrant behavior over this extended interval that the SW fundamental inflation measure did earlier (and continues to in recent years). The basic difficulty is that real unit labor cost or, equivalently, labor's share has declined dramatically since the mid 1990s with little accompanying change in inflation. In section 7 , we provide a summary, conclusion, and discussion of directions for further work.

\footnotetext{
${ }^{2}$ In this study, which involves replication and extension of prior work, there is potential confusion between the results of the original studies and the results of replications/extensions developed along the lines of the studies. We use full names to indicate material which is exactly taken from prior studies, such as the parameter values estimated by Gali and Gertler (1999) and Smets-Wouters (2007). When we refer to data, we use the author's full names because we have carefully reconstructed and extended the data employed these authors, so that the series closely match over the estimation intervals for both prior studies with some small excepections discussed below (see Appendix A for some additional details). Thus, when we discuss the Gali-Gertler and Smets-Wouters measures of labor cost, we are referring to their conceptual constructions and our data set. Fundamental inflation (FI) plays an important role in our study, as it did in Gali and Gertler (1999) and Sbordone (2002). We use abbreviations to indicate our FI constructions. When we refer to GG fundamental inflation, this is our FI construction along Gali-Gertler lines but it differs in some details that we discuss below. The SW fundamental inflation is our construction using Smets-Wouters parameter estimates and our replication/extension of their data set. We think it is an informative construction, but it is not one which they used.
} 


\section{The New Keynesian price equation}

We start by providing a brief account of the motivations for the New Keynesian pricing equation (NKPE) studied in this paper. ${ }^{3}$

\subsection{Forward-Looking Pricing}

The standard New Keynesian modeling of price dynamics is attractive on two dimensions. First, as widely noted, it is an implication of optimization in the Calvo setting, stressing the impact of current and expected future marginal cost on pricing. ${ }^{4}$ Importantly, it captures key dynamic inflation implications of more elaborate models in a tractable manner:

there are a small number of parameters to estimate. ${ }^{5}$ Second, it provides a near-neutral linkage between trend inflation and real marginal cost. ${ }^{6}$ The NKPE may be written as

$$
\pi_{t}=b E_{t} \pi_{t+1}+\lambda \psi_{t}
$$

where $\psi_{t}$ is a measure of real marginal cost, $b$ is a discount factor and $\lambda$ is a nonlinear combination of the discount factor, the expected frequency of price adjustment opportunities, and other structural parameters in various versions of (1). After discussing this benchmark specification, Gali and Gertler (1999) develop a more general hybrid model of inflation that incorporates a backward-looking component to inflation,

$$
\pi_{t}=\gamma_{b} \pi_{t-1}+\gamma_{f} E_{t} \pi_{t+1}+\lambda \psi_{t}+z_{t}
$$

rationalized by the introduction of some price-setters who adopt imitative strategies. In this expression, $z_{t}$ is a residual term, with traditional ambiguity in interpretation.

\footnotetext{
${ }^{3}$ This specification is sometimes called the "New Keynesian Phillips Curve." As it links inflation to marginal cost rather than output or unemployment, we prefer the terminology of Kurmann (2005). This terminology accurately captures its role in NK-DSGE models as one equation in a wage-price block.

${ }^{4}$ Textbook treatments are provided by Gali (2008), Walsh (2010), and Woodford (2003).

${ }^{5}$ See Roberts (1995) for a comparison of specifications.

${ }^{6}$ This near-neutrality property is shared by many models, as noted, for example, by Roberts (1995) and Goodfriend and King (1997)). It holds for state dependent pricing models (see, Dotsey, King and Wolman (1999). More recently, Cogley and Sbordonne (2008) have considered the consequences of time-varying trend inflation within a higher order approximation of the Calvo (1983) model.
} 
There is an extensive literature on identification, estimation and testing of (2).

Macroeconomists are widely divided on whether the frictions embedded in (2) are the most important ones for understanding the interaction of inflation and real variables, as well as on parameter estimates and results of model specification tests. While this literature is valuable, its concerns are not ours: we simply take the parameter estimates in two influential studies and undertake accounting exercises based on these parameter values. These exercises highlight dimensions of success, as in the prior literature, but also substantial empirical difficulties that have not been stressed in the literature.

\subsection{Decomposing inflation}

In our analysis of the links between pricing and real unit labor cost, we consider two decompositions of the sources of inflation.

Decomposition 1 involves the elements of (2) directly, which we term inertia $\left(\gamma_{b} \pi_{t-1}\right)$, expected inflation $\left(\gamma_{f} E_{t} \pi_{t-1}\right)$, real unit labor $\operatorname{cost}\left(\lambda \psi_{t}\right)$ and the residual $\left(z_{t}\right)$. For this, we need an estimate of $E_{t} \pi_{t+1}$ which we construct using two models: (1) an estimated bivariate vector autoregression using $\pi$ and $\psi$ and (2) the estimated Smets-Wouters DSGE model.

Decomposition 2 involves the rational expectations solution of (2)

$$
\pi_{t}=\rho \pi_{t-1}+\lambda_{\psi} \sum_{j=0}^{\infty} \delta^{i} E_{t} \psi_{t+j}+\lambda_{z} \sum_{j=0}^{\infty} \delta^{i} E_{t} z_{t+j}
$$

Given the parameters $\gamma_{b}, \gamma_{f}$, and $\lambda$ the solution parameters $\left(\rho, \delta, \lambda_{\psi}, \lambda_{z}\right)$ are readily and uniquely determined. ${ }^{7}$ To make this decomposition operational, we need estimates of the expectation terms $E_{t} \psi_{t+j}$ and $E_{t} z_{t+j}$ which are computed using a vector autoregression and the SmetsWouters model. The full time series decomposition that we present involves only two components,

\footnotetext{
${ }^{7}$ This a second-order expectational difference equation familiar from Sargent (1978). For the specific formulas applicable in this case, see Gali and Gertler (1999, page 217).
} 


$$
\pi_{t}=\pi_{t}^{\psi}+\pi_{t}^{z}
$$

in that we solve for the path of inflation attributing the $\rho \pi_{t-1}$ separately to $\psi$ and $z$. That is:

$$
\pi_{t}^{\psi}=\rho \pi_{t-1}^{\psi}+\lambda_{\psi} \sum_{j=0}^{\infty} \delta^{i} E_{t} \psi_{t+j}=(1-\rho \mathrm{L})^{-1} \lambda_{\psi} \sum_{j=0}^{\infty} \delta^{i} E_{t} \psi_{t+j}
$$

$$
\pi_{t}^{z}=\rho \pi_{t-1}^{z}+\lambda_{z} \sum_{j=0}^{\infty} \delta^{i} E_{t} z_{t+j}=(1-\rho \mathrm{L})^{-1} \lambda_{z} \sum_{j=0}^{\infty} \delta^{i} E_{t} z_{t+j}
$$

We label $\pi_{t}^{\psi}$ as fundamental inflation, using the terminology of Campbell and Shiller (1998) and Gali-Gertler (1999). ${ }^{8}$

\subsection{A preview of the data and our main results}

Armed with this framework, we can summarize the main results in the paper before going into the details of the models and our analysis. Decomposition 2 uses fundamental inflation $\left(\pi^{\psi}\right)$ to summarize the relation between real unit labor costs $(\psi)$ and inflation $(\pi)$. Because $\pi^{\psi}$ is the discounted sum of expected future $\psi$, and because $\psi$ is highly serially correlated (as we will see), the low frequency movements in $\pi^{\psi}$ mimic the low frequency movements in $\psi$. Thus, an implication of the NKPE is that inflation inherits the low frequency movements of real unit labor costs. The model is useful, in the sense that it explains inflation using real unit labor costs, if these two time series share the same low-frequency behavior. Put differently, if the low-frequency behavior of inflation differs markedly from the low frequency behavior of real unit labor costs, then variables other than real unit labor cost ( $z$ in equation (2)) must be important for explaining inflation.

\footnotetext{
${ }^{8}$ Our measure of fundamental inflation differs slightly from the measure used by Gali and Gertler. Their measure is $\rho \pi_{t-1}+\lambda_{\psi} \sum_{j=0}^{\infty} \delta^{i} E_{t} \psi_{t+j}$ while our measure is $\rho \pi_{t-1}^{\psi}+\lambda_{\psi} \sum_{j=0}^{\infty} \delta^{i} E_{t} \psi_{t+j}$ which differ in the value of lagged inflation. We solve out for the effects of past inflation so as to make our results more conceptually comparable to historical shock decomposition such as those employed in Smets and Wouters (2007). Generally, the Gali-Gertler measure will track inflation more closely, as it incorporates the effects of lagged $z$. But given that the value of the persistence parameter is low (about one-third), the differences between their fundamental inflation and ours is practically small. Further, both measures share the same low frequency properties stressed below.
} 
Figure 1 plots inflation and Gali and Gertler's $\psi$ measure. The two series move together over low frequencies, and the implied fundamental inflation series in Figure 3 captures important movements in inflation. Figure 4 plots inflation and the Smets-Wouters $\psi$ measure. They have different low-frequency behavior, and the fundamental inflation which we construct for the Smets-Wouters model and displayed in Figure 7 differs markedly from actual inflation. Thus, Gali and Gertler's model suggests that real unit labor costs are the main drivers of inflation, while Smets and Wouter's model suggests that other factors $(z)$ play a dominant role. These figures cover the 1960-1999, the (approximate) sample period of interest in early work on the NKPE. Figure 12 extends both $\psi$ measures through 2010, and shows large post1999 declines in both measures. Figure 13 shows that these declines in $\psi$ led to large falls in the corresponding measures of fundamental inflation, but that actual inflation changed little. Thus, the NKPE implies that these measures of $\psi$ have important low-frequency movements unrelated to the real marginal costs important for aggregate inflation or that other factors $(z)$ conspired to prevent a dramatic fall in inflation during the $2000 \mathrm{~s}$.

This preview raises many questions. Why do the $\psi$ measures used by Gali and Gertler and Smets and Wouters differ? What role do the specific parameter values in (2) play in these conclusions? Do these differences in fundamental inflation (decomposition 2) lead to different conclusions about the importance of expected inflation (decomposition 1) in the inflation process? What is the structural interpretation of the $z$-variable in the Smets and Wouters model and how does it interact with $\psi$ ? Why have real unit labor costs fallen so dramatically over the past decade? And finally, given these results, is the NKPE a useful empirical model for inflation? The remainder of the paper takes up these questions. 


\section{Accounting with just the NKPE}

We now investigate how the hybrid NKPE (2) accounts for inflation during the 19601999 period, using our two decompositions. For this purpose, we use the parameter values from Gali and Gertler (1999) displayed in Table 1.

\subsection{Inflation and RULC}

The central feature of the New Keynesian pricing theory is a link to real marginal cost, most frequently proxied by real unit labor cost in applied work. Figure 1 shows the comovement of GDP deflator price inflation $(\pi)$ and $\log$ real unit labor cost $\psi$ (measured as the logarithm of the ratio of nominal compensation per hour to nominal output per hour in the nonfarm business sector). The real unit labor cost series moves together with inflation, notably during the 1970s and 1980s.

To operationalize our decompositions, we need to construct $E_{t} \pi_{t+1}$ for the first and $\lambda_{\psi} \sum_{j=0}^{\infty} \delta^{i} E_{t} \psi_{t+j}$ for the second. In each case, we follow Gali and Gertler (1999) and use a bivariate VAR that includes four lags of $\pi$ and $\psi$ to forecast the relevant variables. We consequently call these GG-VAR decompositions. Additional computation details on the fundamental inflation decomposition are provided in section 5 below.

\subsection{Results from Decomposition 1}

The results of decomposition 1 are displayed in Figure 2. We find that expected inflation is the dominant source of actual inflation in Figure $2\left(\gamma_{f} E_{t} \pi_{t+1}\right)$. A smaller part of inflation is due to inertial effects $\left(\gamma_{b} \pi_{t-1}\right.$ is shown in panel A). Because the coefficient on real unit labor cost is small $(\lambda=0.15)$, the real unit labor cost component $\left(\lambda \psi_{t}\right)$ accounts for little of the variation in inflation. Finally, residual influences $\left(z_{t}=\pi_{t}-\left[\gamma_{f} E_{t} \pi_{t+1}+\gamma_{b} \pi_{t-1}+\lambda \psi_{t}\right]\right)$ are quantitatively important.

\subsection{Results from Decomposition 2}

While current real unit labor costs accounted for little of the variation in inflation using decomposition 1, matters are very different when expected future real unit labor costs are included using decomposition 2. Figure 3 displays the fundamental component $\pi_{t}^{\psi}$ of inflation 
over 1960-1999 (the comparable Figure 2 in Gali and Gertler (1999) is for a slightly shorter sample period, 1961-1997). Given (4), the residual component $\pi_{t}^{z}$ is just the difference between the inflation and its fundamental component $\left(\pi_{t}^{z}=\pi_{t}-\pi_{t}^{\psi}\right)$.

Our GG fundamental inflation series does a reasonable job of tracking actual inflation during the interval that such expectations-augmented pricing equations were designed to explain: the rise in inflation during the late 1960s, the sustained high inflation of the 1970s, and the unwinding of inflation in the early 1980s. Indeed, it is the close correspondence of fundamental inflation with actual inflation over these periods that many researchers found intriguing when they were first displayed in Gali and Gertler (1999) and Sbordone (2002). ${ }^{9,10}$

\subsection{Implications for modeling}

The tractability and empirical success of the NKPE led it to become a standard, if controversial, element of textbook presentations of the New Keynesian approach to macroeconomics. ${ }^{11}$ More important for our purposes, the NKPE was imported into modern DSGE models employed by central banks around the world, as discussed in the introduction.

With many central banks undertaking some version of inflation targeting, Figures 2 and 3 capture why the NKPE approach was attractive as part of a larger model. Figure 2 is in line with the idea that inflation control requires the management of expectations, while Figure 3 suggests that aggregate demand policies -- which affect inflation through real marginal cost in these models -- could be used for this purpose. At the same time, the parameter estimates of

\footnotetext{
${ }^{9}$ The relationship is less strong in the early and late periods of our sample, with much of poor performance in the later period arising from revisions in the real unit labor cost data that were not available to Gali, Gertler, and Sbordone.

${ }^{10}$ The estimate of fundamental inflation is subject to substantial sampling variability - that is, appropriately computed confidence bands in figure 3 are wide. Because fundamental inflation is a discounted sum of expected future values of $\psi$, the sampling variability arises from uncertainty in the discount factor $\delta$ and the parameters used to construct the forecasts. Because $\delta$ is large, uncertainty about the long-run properties of the forecasting model are particularly important. Characterizing this uncertainty is complicated because the variables in the model, $\psi$ and $\pi$, are highly serially correlated so the VAR has roots near the unit circle, i.e., approximate "unit roots." We have therefore not attempted to compute appropriate confidence bands. However, to give you some sense of the uncertainty, consider a simple version of the model in which $\psi$ follows a univariate $\operatorname{AR}(1), \psi_{i}=\phi \psi_{t-1}+u_{t}$, in which case fundamental inflation is given by $(1-\delta \phi)^{-1}(1-\rho \mathrm{L})^{-1} \lambda_{\psi} u_{t}$. Considering uncertainty in the first term, $(1-\delta \phi)^{-1}$, the $95 \%$ confidence interval for $\phi$ computed using Stock's (1991) method ranges from 0.861 to 1.012 , and using the point estimate of $\delta$ from table $1(\delta=0.876)$ yields a $95 \%$ confidence interval for $(1-\delta \phi)^{-1}$ that ranges from 4.1 to 8.8 , so that the scale varies by a factor of model that 2 . Additional uncertainty arises from the estimated values of $\delta$ and $\rho$, and the persistence in $\pi$.

${ }^{11}$ See Gali (2008), Walsh (2010), and Woodford (2003).
} 
Table 1 indicate that major movements in real marginal cost must arise because the parameter $\lambda$ is small (at 0.15 for the Gali-Gertler study) ${ }^{12}$. With expected inflation held constant, cutting annualized inflation by one percent in the current quarter thus requires that real marginal costs fall by 6 percent. The NKPE thus incorporated the idea of a challenging short-term trade-off if expectations are fixed, while having little long-run trade-off with changing expectations.

Sbordone (2002) highlights the promise of the NKPE single equation estimates as follows: "nominal rigidities are a reasonable component of a complete macroeconomic model. The failure of existing general equilibrium models which incorporate nominal rigidities to account for all features of observed time series (see King and Watson (1996); Christiano et al. (1997)) may not be due to a misspecified pricing equation, but rather to other features of these models (that they share with standard real business cycle models)." We now turn to the analysis of a rich DSGE model.

\section{Accounting with the canonical NK-DSGE model}

While we can learn much about inflation and its relation to unit labor cost from analyzing the NKPE in isolation, it must be imbedded in a complete structural econometric model to answer questions about interactions of inflation and other variables (output, interest rates, employment, etc.) and questions about the structural sources of variability and covariability. In this paper, we study DSGE inflation dynamics using the model of Smets and Wouters (2007).

Along with many other builders of modern DSGE models, Smets and Wouters employ an alternative route to a hybrid NKPE than that provided by Gali and Gertler (1999): they assume that a fraction of firms can dynamically index their prices to the inflation rate, rather than keeping these fixed in nominal terms, a mechanism popularized by Christiano, Eichenbaum and Evans (2005) and developed in detail by Eichenbaum and Fisher (2007). ${ }^{13}$ While this story provides a different motivation for lagged inflation in the NKPE, the result also takes the form (2), albeit with a different link between that equation's coefficients and structural parameters. The Smets-Wouters study also employs a different sample period, different data,

\footnotetext{
${ }^{12}$ Note that their estimate is just under .04 , but is for a quarterly inflation rate. As we are using annualized inflation rates, we multiply by 4 to obtain the .15 value referenced in the text.

${ }^{13}$ The fact that actual micro prices are held fixed in nominal terms rather than adjusted mechanically according to an index has led to substantial criticism of the indexation mechanism (see, for example, Collard and Dellas (2006)).
} 
and a different estimation procedure. However, from the structural parameters estimated by Smets and Wouters estimates (2007, table 1), we can calculate the implied values of $\lambda$, $\gamma_{f}$, and $\gamma_{b}:$ we list these in Table 1 and use them throughout the paper.

The Smets and Wouters (2007) model for the U.S. economy is a medium scale DSGE model. It features a neoclassical flexible price "core" that is a real business cycle model augmented with real frictions in investment (cost of changing the rate of investment) and consumption (habit persistence) that is subjected to shocks to general production and investment-specific technology. ${ }^{14}$ Monopolistic competition elements are present in both labor and product markets, with variable elasticity aggregators of the Kimball (1995) form and with overhead costs absorbing profits. Nominal stickiness along Calvo (1983) lines is introduced into both product and labor markets as in Erceg, Henderson, and Levin (2000). As previously discussed, there are additional price and wage inertia mechanisms -- partial indexation -embedded in earlier DSGE models. Finally, the model is closed with an interest rate rule for monetary policy in the tradition of Taylor (1993).

The Smets-Wouters model is estimated using Bayesian methods along the lines advocated by An and Schorfheide (2007). A major impetus to DSGE model development was provided by the Smets and Wouters (2007) finding that the model was competitive in fit and forecasting with standard and Bayesian VAR models.

As a medium scale DSGE model, the Smets and Wouters framework model contained predictions for a substantial number of macroeconomic variables (about 40). In estimation, the authors sought to match 7 series of major interest to macroeconomists and policymakers: the growth rates of output, consumption, and investment; the growth rates of nominal prices and wages; the level of labor input (aggregate hours); and the short-term nominal interest rate. The authors introduced the minimum number of structural shocks necessary to avoid a stochastic singularity. They specified these as a shock to total factor productivity, an investment specific technology shock, a government purchase shock, an interest rate spread shock, shocks to price and wage markups, and a monetary policy shock.

Importantly for our analysis, Smets and Wouters treat $z_{t}$ differently from Gali and Gertler along two dimensions. First, they give $z_{t}$ a structural interpretation as the exogenous

\footnotetext{
${ }^{14}$ Variable depreciation arising from endogenous capacity utilization and overhead production costs also augment the core neoclassical model.
} 
component of a time-varying markup of price over marginal cost. Second, they specify its evolution as

$$
z_{t}=\rho_{p} z_{t-1}+\eta_{p t}-\mu_{p} \eta_{p t-1}
$$

with $\rho_{p}=0.89$, and $\mu_{p}=0.69 .{ }^{15}$ Processes with substantial moving average parameters have been used extensively in the literature on forecasting inflation with univariate time series models (see, for example, Nelson and Schwert (1978) and Stock and Watson (2007)). The MA component of the specification allows a forecasting model to capture the fact that there are important high frequency components of inflation since a value of $\mu_{p}=0.69$ means a current forecast error induces a forecast revision that is only about 0.2 of the error $\left(E_{t} z_{t+1}-E_{t-1} z_{t+1}=\right.$ $\left.\left(\rho-\mu_{p}\right) \eta_{p t}=0.21 \eta_{p t}\right)$. Nevertheless, since $E_{t} z_{t+j}-E_{t-1} z_{t+j}=\rho^{j}\left(\rho-\mu_{p}\right) \eta_{p t}$, the implied price markup variations are highly persistent.

\subsection{Inflation and Modified RULC}

The overhead structure of production in Smets and Wouters (2007) means that standard real unit labor cost does not accurately measure real marginal cost. However, it can be measured by modified real unit labor cost,

$$
\psi_{t}=\left(W_{t}-P_{t}\right)+n_{t}-\Phi^{-1} y_{t}
$$

where $\Phi$ is the ratio of total cost (including overhead cost) to total output. ${ }^{16}$ The value of $\Phi$ estimated by Smets and Wouters implies that the typical firm has overhead cost that are approximately $60 \%$ of its total cost, so that $\Phi \approx 1.6$. The Gali and Gertler measure of real unit labor cost takes the form as (8), but with $\Phi=1$. As a practical matter, the Smets and Wouters unit labor cost is thus less responsive to movements in output relative to real compensation.

\footnotetext{
${ }^{15}$ These numbers are the posterior means of the parameters, provided in Table 2 of Smets and Wouters (2007). In their work, the parameter is called $\rho_{p}$ to distinguish it from the AR parameter of other shock processes.

${ }^{16}$ While the Smets-Wouters -DSGE model was not directly fit to match modified real unit labor cost, it was fit to match the joint behavior of its ingredients $(W, n, P, y)$ and modified real unit labor cost is one of the many variables provided by the Smets-Wouters Dynare code that is employed to estimate and simulate the Smets-Wouters -DSGE model.
} 
The inflation dynamics of the DSGE model obey the NKPE (2) using this modified unit labor cost construction. Figure 4 shows the inflation and modified real unit labor cost series which we employ in our analysis of the Smets and Wouters DSGE model. Note that GDP inflation is the same as in Figure 1; it is the labor cost series which is different. ${ }^{17}$

\subsection{Decomposing inflation in the Smets-Wouters model}

Smets and Wouters (2007) do not use either of our decompositions, but rather provide a historical decomposition of inflation into components arising from the various shocks, as in standard vector autoregression analysis. Figure 5 displays the DSGE model's decomposition of the historical behavior of inflation into price markup shocks, wage markup shocks, monetary policy shocks, and all other shocks. ${ }^{18}$ The DSGE framework allows a further breakdown of the last panel into consequences of shocks to government purchases, general productivity, investment-specific productivity, and an interest rate spread. However, given the focus of the present study and to avoid unwieldy figures, we opted for a more limited breakdown.

Some macroeconomists would surely be surprised by this decomposition, which attributes most of the variation in inflation to price and wage shocks. But Keynesian economists have long suggested that most of inflation is due to such factors. Other macroeconomists would point to the fact that the DSGE model indicates that monetary policy exerted an important effect on inflation -- first positive and then sharply negative -- during the late 1970s and early 1980s.

We now turn to the results of our decompositions.

\footnotetext{
${ }^{17}$ Gali-Gertler and Smets-Wouters also differ in some details of their measurements of the components of real marginal cost $(W, P, n$, and $y)$. Gali and Gertler use measures for the non-farm business sector for all of these components. Smets and Wouters use full-economy measures for $y$ and $P$ (real GDP and the GDP deflator), nominal compensation per hour in the non-farm business sector for $W$, and compute $n$ (total hours of employment) using average weekly hours in the non-farm business sector multiplied by employment in the total economy (from the U.S. household survey). Finally, because $n$ and $y$ are in per-capita terms, Smets and Wouters divide hours and output by a measure of population; this adjustment is not necessary for Gali and Gertler (because $\Phi=1$ for their measurement of $\psi$ ). Edge and Gurkaynak (2010) discuss measurement problems with the population series used by Smets and Wouters. Our analysis is based on a modified version of the series that eliminates these problems. See Appendix A for details.

${ }^{18}$ Our Figure 5 conveys similar content to Figure 4 in Smets and Wouters (2007), but is tailored to our purposes. Smets and Wouters (2007) combine price and wage markup shocks in providing the historical decomposition of inflation.
} 


\subsection{Decomposition 1}

Just as we did for the Gali-Gertler NKPE parameter values, we can use (2) and the Smets-Wouters NKPE parameter values to decompose $\pi_{t}$ into a component associated with lagged inflation ("inertia"), expected future inflation, real unit labor cost ( $\psi_{t}$, now using the modified unit labor cost series), and residual ( $z_{t}$ in equation (2)). However, to generate inflation expectations, we now use the inflation forecast from the full Smets and Wouters (2007) DSGE model, so that we label the decompositions as SW-DSGE.

The results are shown in Figure 6. Comparing these to the corresponding figure for our replication of Gali and Gertler (Figure 2) leads to the same finding: expected inflation is the dominant force in current level of inflation. Evidently this conclusion is robust to the range of parameter values encompassed by Gali-Gertler and Smets-Wouters as well as to the differences in the way real marginal cost $(\psi)$ is measured.

\subsection{Decomposition 2}

Similarly, we can use (5) and (6) to break $\pi_{t}$ into a marginal cost component (“fundamental inflation," $\left.\pi^{\psi}\right)$ and price mark-up component $\left(\pi^{z}\right)$ for the DSE model. Each component depends on current and expected future values: we use the full Smets and Wouters

DSGE model to construct the forecasts, for example $\sum_{j=0}^{\infty} \delta^{j} E_{t} \psi_{t+j}$ in fundamental inflation.

Figure 7 provides actual inflation and our constructed SW-DSGE fundamental inflation $\pi^{\psi}$. While Figure 3 shows a plausibly close relation between the actual inflation $\pi$ and the GG$\operatorname{VAR} \pi^{\psi}$ over much of the sample period, no such relation is evident in Figure 7. Notably, since $\pi=\pi^{\psi}+\pi^{z}$, Figure 7 instead suggests that over the 1960-1999 period, inflation was the result of two countervailing trends: a large downward trend in the marginal cost component, $\pi^{\psi}$, that was essentially cancelled out by an upward trend in the price markup component, $\pi^{z}$.

\subsection{The Inflation-Unit Labor Cost Puzzle}

The behavior of inflation within the DSGE setup thus provides a puzzle, which we can pose as a series of questions. Why are the single equation and DSGE results for fundamental inflation so different? Is it because the NKPE parameters in Table 1 are not the same? Is it because unit labor cost, as modified by Smets-Wouters, is a poor proxy for marginal cost, while 
the GGS construction better captures marginal cost? Is it because, as with Sbordone's (2002) appraisal of an earlier generation of sticky price DSGE models, there is something crucially wrong with the rest of the Smets and Wouters model as a driving process for inflation? Or is it something else about the comovement of inflation and real unit labor cost?

We now turn from being accountants to being detectives.

\section{Understanding fundamental inflation}

As we have seen, the estimate of fundamental inflation based on the GG-VAR model indicates that much of the variation in inflation over 1960-1999 was associated with variation in expected future marginal cost (i.e., fundamental inflation shown in Figure 3). By contrast, our SW-DSGE construction of fundamental inflation is not close to variations in actual inflation. In this section, we investigate why the two models yield such dramatically different fundamental inflation series over 1960-1999.

\subsection{Common computational framework}

To sort through the sources of differences in the two fundamental inflation measures, it is useful to introduce some notation and a common computational framework. For both the GG fundamental inflation construction (based on a VAR) and the SW construct (based on the DSGE model), future values of $\psi$ are forecast using a state-vector, say $d_{t}$ which evolves as

$$
d_{t}=M d_{t-1}+u_{t}
$$

where $u_{t}$ is an unforecastable error vector. For the GG measure of fundamental inflation, $d$ contains current and lagged values of inflation and real unit labor, when we place their VAR in the companion form (9). For the SW measure, $d$ is the state-vector for the DSGE model. In both models $\psi$ is linearly related to $d$, that is

$$
\psi_{t}=\iota_{\psi}{ }^{\prime} d_{t}
$$


where, for the GG-VAR model $\iota_{\psi}$ is a selection vector that extracts $\psi$ from the state vector $d$, and for the Smets-Wouters-DSGE model $\iota_{\psi}$ is a vector of coefficients. Thus, each version of fundamental inflation can be written as

$$
\pi_{t}^{\psi}=\rho \pi_{t-1}^{\psi}+t_{\psi}{ }^{\prime} \lambda_{\psi}[I-\delta M]^{-1} d_{t}=(1-\rho \mathrm{L})^{-1} \iota_{\psi}{ }^{\prime} \lambda_{\psi}[I-\delta M]^{-1} d_{t}
$$

where the expression uses the definition of fundamental inflation in (5) together with the formula for computing expected discounted $\psi$ familiar from Campbell and Shiller (1988).

Equation (11) highlights two important differences in the GG-VAR and SW-DSGE measures of fundamental inflation. The first is that there are a different set of parameters for the hybrid NKPE, that is the values of $\rho, \lambda_{\psi}$, and $\delta$ in (11). ${ }^{19}$ In what follows we denote the hybrid NKPE parameters by $\theta=\left(\rho, \lambda_{\psi}, \delta\right)$, with $\theta^{G G}$ and $\theta^{S W}$ denoting the parameter values implied by the Gali-Gertler and Smets-Wouters structural parameter estimates. The second difference is that there is a different forecasting model, that is the values of $M$ and $d_{t}$ in (11). Finally, a third important difference is that the data used for forecasting $(d)$ is not the same across the two studies, as we discuss further below.

More abstractly, based on (11) we can represent fundamental inflation as $\pi^{\psi}(\theta, M, \psi)$, indicating its dependence on NKPE parameters, on the forecasting model, and on the empirical measure of marginal cost employed. (Inflation enters, too, but it is a common time series and cannot be the source of any differences given these other elements). Using this notation, we have so far looked at $\pi^{\psi}\left(\theta^{G G}, M^{G G-V A R}, \psi^{G G}\right)$ in Figure 3 and $\pi^{\psi}\left(\theta^{S W}, M^{S W-D S G E}, \psi^{S W}\right)$ in Figure 7.

\subsection{Different cost measures}

As discussed above, one source of the difference between the fundamental inflation measures is the empirical measure of $\psi$. Figure 8 plots the standard real unit cost measure used by Gali and Gertler and the modified version used by Smets and Wouters. A striking feature of the plot is the different low-frequency behavior of the two series, particularly post-1980, with the Smets-Wouters modified measure showing a more pronounced decline from 1980 until the

\footnotetext{
${ }^{19}$ Recall from section 2 above that these parameters are functions of $\gamma_{b}, \gamma_{f}$, and $\lambda$ : the implied values of $\rho$, $\lambda_{\psi}$, and $\delta$ are listed in Table 1. In turn, for the Smets-Wouters model, $\gamma_{b}, \gamma_{f}$, and $\lambda$ are functions of deeper structural parameters.
} 
mid 1990s. Detrended values of the series are shown in Appendix B; the detrended series generally move together: the correlation between the detrended series is 0.66. Evidently, differences in low-frequency behavior of $\psi^{G G}$ and $\psi^{S W}$ are potential souces of the differences in the two fundamental inflation series.

\subsection{An approximation to fundamental inflation}

To simplify matters, we find it useful to interpret the various versions of $\pi^{\psi}$ using an approximation and a related pair of approximation coefficients. To motivate this approximation, consider the GG-VAR forecasting model in which $d_{t}$ contains current and lagged values of $\psi$ and $\pi$. From (11), fundamental inflation will then depend on a distributed lag of $\psi$ and $\pi$,

$$
\pi_{t}^{\psi}=\beta_{\psi}(\mathrm{L}) \psi_{t}+\beta_{\pi}(\mathrm{L}) \pi_{t}
$$

where the polynomials in the lag operator, $\beta_{\psi}(\mathrm{L})$ and $\beta_{\pi}(\mathrm{L})$, depend on $\theta$ and $M$. By rearranging the state vector (which one can always do without changing any implications of the model (12)) we create an alternative equivalent form,

$$
\pi_{t}^{\psi}=\beta_{\psi}(1) \psi_{t}+\beta_{\pi}(1) \pi_{t}+\omega_{\psi}(\mathrm{L}) \Delta \psi_{t}+\omega_{\pi}(\mathrm{L}) \Delta \pi_{t}
$$

This new formulation (13) pulls out a single level of $\psi$ and $\pi$ together with lags of the first differences $\Delta \psi_{t}=\psi_{t}-\psi_{t-1}$ and $\Delta \pi_{t}=\pi_{t}-\pi_{t-1}$. In (13) the coefficients on the levels of $\psi$ and $\pi$ are the sums of the coefficients in distributed lag in the original equation (12) so they can be written as $\beta_{\psi}(1)$ and $\beta_{\pi}(1)$.

The rearrangement yielding (13) lets us break up $\pi_{t}^{\psi}$ into a level component, $\beta_{\psi}(1) \psi_{t}+$ $\beta_{\pi}(1) \pi_{t}$, and an additional component that is a distributed lag of changes $\left(\omega_{\psi}(\mathrm{L}) \Delta \psi_{t}+\right.$ $\left.\omega_{\pi}(\mathrm{L}) \Delta \pi_{t}\right)$. Because $\psi$ and $\pi$ are persistent and because $\pi_{t}^{\psi}$ depends on long-run forecasts of future $\psi$ most of the variability in $\pi_{t}^{\psi}$ arises from the level component, $\beta_{\psi}(1) \psi_{t}+\beta_{\pi}(1) \pi_{t}$, and 
the distributed lag of changes, $\omega_{\psi}(\mathrm{L}) \Delta \psi_{t}+\omega_{\pi}(\mathrm{L}) \Delta \pi_{t}$, has relatively little effect on $\pi_{t}^{\psi}$. Thus, we will approximate $\pi_{t}^{\psi}$ by $\tilde{\pi}_{t}^{\psi}$, where

$$
\pi_{t}^{\psi} \approx \tilde{\pi}_{t}^{\psi}=\beta_{\psi}(1) \psi_{t}+\beta_{\pi}(1) \pi_{t}
$$

The advantage of this approximation is that it allows us to characterize differences in fundamental inflation using only the coefficients $\beta_{\psi}(1)$ and $\beta_{\pi}(1)$, as well as the measure of real marginal cost, $\psi$.

This approximation cannot be directly used for the SW-DSGE measure of $\pi_{t}^{\psi}$ because it is based on a state vector $d$ that contains variables other than $\psi$ and $\pi$, so that (12) does not hold. To overcome this problem, we compute an approximation in two steps for the SW fundamental inflation. In the first step, we use the DSGE model to compute the model-implied population values of the autocovariances and cross-autocovariances for $\pi$ and $\psi$ : from these, we compute the implied bivariate VAR coefficients for $\psi$ and $\pi$ with the same number of lags used in the GG-VAR fundamental inflation. In the second step, we compute the approximation (12) using the model-based bivariate VAR coefficients and data on $\pi$ and $\psi$.

Figure 9 shows the GG-VAR and SW-DSGE measures of fundamental inflation ( $\pi_{t}^{\psi \prime}$, from Figures 3 and 7) together with their approximations ( $\tilde{\pi}_{t}^{\psi}$ using (14)) and where each approximation is based on a bivariate VAR, as discussed above. The GG approximation uses the Gali-Gertler measure of $\psi$ (real unit labor cost) and the SW approximation uses the SmetsWouters measure of $\psi$ (modified real unit labor cost).

In panel A of Figure 9, we see that the GG constructs, $\pi_{t}^{\psi /}$ and $\tilde{\pi}_{t}^{\psi}$, essentially coincide: thus, we can capture most of the variation in $\pi_{t}^{\psi}$ using to coefficients $\beta_{\pi}^{G G}(1)$ and $\beta_{\psi}^{G G}(1)$ along with the levels of $\psi_{t}^{G G}$ and $\pi_{t}$. In panel B of Figure 9, we see that the approximation is less than perfect for the SW constructs, but $\tilde{\pi}_{t}^{\psi}$ does capture much of variation in $\pi_{t}^{\psi}$ (the correlation between the two series is 0.97 ). So, we view the approximation as reasonable in each case.

How does the approximation $\tilde{\pi}_{t}^{\psi}$ help us in our detective work? We want to learn about the relative importance of NKPE model parameters $\theta$ the forecasting model parameters $M$, and 
the empirical measure of marginal cost $\psi$ in generating the striking difference between the GGVAR and SW-DSGE measures of fundamental inflation. First, we can see that the distributed lag weights $\beta_{\psi}(\mathrm{L})$ and $\beta_{\pi}(\mathrm{L})$ in (12) depend only on $\theta$ (the parameters in the NKPE) and $M$ (the state-transition matrix that governs the forecastability of future values of real marginal cost), equations (12) and (14): we can thus change $\theta$ and $M$ separately and determine the effect on just two numbers, $\beta_{\psi}(1)$ and $\beta_{\pi}(1)$ Secondly, we see that the particular measure of marginal cost $\psi$ plays a role. Taking these points together, any differences in measures of fundamental inflation can be attributed to the choice of $\theta, M$, and a particular empirical measure of real marginal cost $\psi$. This allows us to investigate the source of the differences between the two fundamental inflation measures by changing the values of $\theta, M$, and $\psi$.

\subsubsection{Mixing and Matching $\theta, M$, and $\psi$}

Table 2 summarizes the behavior of $\pi^{\psi}(\theta, M, \psi)$, for various values of $\theta, M$, and $\psi$. Five summary statistics are shown for each measure of fundamental inflation: $\beta_{\psi}(1)$ and $\beta_{\pi}(1)$ are the coefficients from (14), $\sigma\left(\tilde{\pi}^{\psi}\right)$ is the standard deviation of $\tilde{\pi}^{\psi}$ over the 1960-1999 sample period, $\operatorname{cor}\left(\pi^{\pi}, \tilde{\pi}^{\psi}\right)$ is the correlation between fundamental inflation and the approximation in (14), and $\operatorname{cor}\left(\pi, \tilde{\pi}^{\psi}\right)$ is the correlation of actual inflation with $\tilde{\pi}^{\psi}$.

The table highlights two sets of benchmark results, presented in the boldfaced rows 1 and 6. These tabulate information on the fundamental inflation and approximation series displayed in Figure 9. First, row 1 of the table shows results for the GG-VAR fundamental inflation and its approximation, based on (14) and plotted in Panel A of Figure 9. Row 1 indicates that the approximation depends positively on both $\psi$ and $\pi$ with weights $\beta_{\psi}(1)=1.30$ and $\beta_{\pi}(1)=0.26$; that it has a volatility just slightly higher than actual inflation $\left(\sigma\left(\tilde{\pi}^{\psi}\right)=2.90\right.$ versus $\sigma(\pi)=2.53)$; that the approximation is nearly perfect $\left.\operatorname{cor}\left(\pi^{\pi}, \tilde{\pi}^{\psi}\right)=0.99\right)$; and that it captures many of the movements in actual inflation $\left(\operatorname{cor}\left(\pi, \tilde{\pi}^{\psi}\right)=0.61\right)$ over the $1960-1999$ sample period. Second, row 6 shows the results for the SW-DSGE series plotted in Panel B of Figure 9. In contrast to the results just discussed, row 6 shows that the SW-DSGE approximation places a larger positive weight on $\psi\left(\beta_{\psi}(1)=1.89\right)$, but a negative weight on $\pi$ 
$\left(\beta_{\pi}(1)=-0.89\right)$; that it has a volatility much higher than actual inflation $\left(\sigma\left(\tilde{\pi}^{\psi}\right)=5.22\right)$; that it is a good, but not perfect approximation $\left(\operatorname{cor}\left(\pi^{\pi}, \tilde{\pi}^{\psi}\right)=0.97\right)$; and that it is essentially uncorrelated with actual inflation $\left(\operatorname{cor}\left(\pi, \tilde{\pi}^{\psi}\right)=0.02\right)$.

To look behind these stark differences, the other rows of the table summarize the behavior of $\pi^{\psi}$ computed using different permutations of $\theta, M$, and $\psi$. For example, row 2 shows results for $\tilde{\pi}^{\psi}\left(\theta^{\mathrm{S} W}, M^{\mathrm{GG}-V A R}, \psi^{G G}\right)$, i.e., an approximation computed using the GG measure of real unit labor cost $\left(\psi^{G G}\right)$ and forecasting model $\left(M^{\mathrm{GG}-V A R}\right)$ but using the SmetsWouters NKPE parameter values $\left(\theta^{\mathrm{S} W}\right)$. Comparing the various rows in the table leads to the conclusion that all of the $(\theta, M, \psi)$ ingredients play complementary roles in explaining the differences between the GG and SW measures of fundamental inflation. We discuss each ingredient in turn.

To understand the role of the parameter values, compare the row 2 information on $\tilde{\pi}^{\psi}$ $\left(\theta^{\mathrm{S} W}, M^{\mathrm{GG}-V A R}, \psi^{G G}\right)$, and the benchmark in detail. Note that the Smets-Wouters estimates in Table 1 put more weight on expected future inflation (higher $\delta$ ) in the NKPE. In turn, this leads to more weight placed on expected future values of $\psi$ in fundamental inflation. (From Table 1, the Smets-Wouters discount factor is $\delta^{S W}=.998$ while the corresponding Gali-Gertler value is $\delta^{G G}=0.876$ ). Turning to our approximation, with $M$ and $\psi$ held constant (based on GG), $\beta_{\psi}(1)$ is slightly smaller and $\beta_{\pi}(1)$ is substantially larger (rising from 0.26 in row 1 to 0.99 in row 2 ) computed using $\theta^{S W}$ rather than with $\theta^{G G}$. But it cannot be the Smets-Wouters parameters alone that lead to the difference, as row 2 of Table 2 also shows that (i) the approximation becomes more highly correlated with actual inflation; and (ii) it also becomes too volatile relative to actual inflation.

To understand the role of the forecasting model $M$, start by looking at the first three rows of the table: each uses $M^{G G-V A R}$ i.e, forecasts constructed using a VAR estimated using the GG $\psi$ measure. These measures are different on some dimensions (such as volatility and correlation with actual inflation), but they all place a weight on the $\psi$ measure that is positive and less than the corresponding values using $M^{S W-V A R}$ or $M^{S W}$ and a weight on $\pi$ that is positive $\left(\beta_{\pi}(1)=0.26\right.$ in rows 1 and 3 and is 0.99 is row 2$)$. By contrast, there is a very different pattern in all of the other rows of the table: the weight placed on $\psi$ is positive and large, and the weight 
placed on $\pi$ is negative $\left(\beta_{\pi}(1)<0\right)$. Said differently, with $\psi$ fixed, increases in $\pi_{t}$ predict decreases in future $\psi$ when the SW forecasting model is used, but predict increases in $\psi$ when the GG forecasting model is used. This finding holds robustly: (i) it occurs when the forecasting model is estimated using the Smets-Wouters measure of $\psi$, either directly in a VAR in rows 4 and $5\left(M^{\text {SW-VAR }}\right)$ or indirectly using the complete Smets-Wouters DSGE model in rows 6 and 7 $\left(M^{S W}\right)$ and (ii) it occurs when the parameters are those of Gali-Gerler (lines 4 and 7) or SmetsWouters (lines 5 and 6). ${ }^{20}$

Finally, to understand the role of the empirical measure of $\psi$ in fundamental inflation, notice that $\operatorname{cor}\left(\pi^{\pi}, \tilde{\pi}^{\psi}\right)$ is close to one for all rows in the table (that is for both the GG and SW measures). This is consistent with the approximation equation (14) that shows, for a given value of $\beta_{\psi}(1)$, the measure of $\psi$ has a direct effect on the approximate measure of fundamental inflation.

Taken together these results suggest a two-part explanation for the trending behavior of $\pi^{\psi}$ in the SW-DSGE fundamental inflation construction displayed in Figures 7 and 9. In the first half of the sample period (1960-1980), the steep decline in $\pi^{\psi}$ arises largely from upward trend in actual inflation via the $\beta_{\pi}(1) \pi_{t}$ component of our approximation to fundamental inflation. This curious result arises because there is a negative value of $\beta_{\pi}(1)=-0.89$ in line 6 of Table 2 . In the second half of the sample period, there is little low frequency variation in inflation. However, the Smets-Wouters modified real unit labor cost measure shows a marked decline which, when amplified by $\beta_{\psi}(1)=1.89$ in line 6 of Table 2 , leads to a steep decline in the measure of fundamental inflation that we have constructed for the Smets-Wouters model and data. A pronounced decline does not arise in the benchmark GG-VAR measure (displayed in Figure 9A) of fundamental inflation, because our approximation indicates that their forecasting model does not imply a negative relationship between $\pi$ and fundamental inflation (that is,

\footnotetext{
${ }^{20}$ To help understand the role of $M$ for the sign of $\beta_{\pi}(1)$ consider the VAR(1) model, $y_{t}=\Phi y_{t-1}+\varepsilon_{t}$, where $y_{t}=\left(\psi_{t}\right.$ $\left.\pi_{t}\right)^{\prime}$. In this case, the discounted sum of future expectations of $y$ is given by $A y_{t}$, where $A=(\mathrm{I}-\delta \Phi)^{-1}$, so that $\beta_{\pi}(1)$ is proportional to $A_{12}$. When $|A|$ is positive, the sign of $\beta_{\pi}(1)$ is determined by the sign of $\Phi_{12}$. When $\Phi_{12}$ is positive, high values of inflation today predict high values of $\psi$ in the future; when $\Phi_{12}$ is negative, high values of inflation today predict low values of $\psi$ in the future. In the general $\operatorname{VAR}(p)$ model $y_{t}=\Phi(\mathrm{L}) y_{t-1}+\varepsilon_{t}$, the same result holds as an approximation with $\Phi(1)$ (the sum of the coefficients) replacing $\Phi$. In the VAR represented by $M^{\text {GG-VAR }}, \Phi(1)_{12}$ is positive $\left(\Phi(1)_{12}=0.03\right)$, while it is negative in the approximate VAR constructed using $M^{S W}$ $\left(\Phi(1)_{12}=-0.15\right)$ and when using the VAR estimated directly using the Smets-Wouters data, $M^{S W-V A R}\left(\Phi(1)_{12}=\right.$ $-0.03)$.
} 
$\left.\beta_{\pi}(1)>0\right)$ and because the Gali-Gertler measure of real unit labor cost does not show the same trend decline evident in the Smets-Wouters cost measure.

\subsection{DSGE structural interpretation}

We now turn to understanding aspects of the comovement of inflation and cost within the DSGE model.

\subsubsection{Why does high inflation forecast low cost?}

While this forecasting exercise explains the empirical mechanics underlying the lowfrequency behavior of SW fundamental inflation, it doesn't explain how this behavior is manifested in the Smets and Wouters structural DSGE model. For example, what is it in the structural model that explains why high inflation today predicts low future values of marginal cost? That is, what is it in the Smets-Wouters model that leads to a negative value of $\beta_{\pi}(1)$ ? This negative value is particularly puzzling because the underlying economics of the NKPE indicate just the opposite: if today's inflation arises from expected future values of real marginal cost, then high inflation predicts high (not low) values of future marginal cost.

To see how the model can generate a value of negative value of $\beta_{\pi}(1)$, recall that inflation $\pi_{t}$ is completely decomposed into a component $\pi^{\prime}$ (fundamental inflation, specified in (5)) associated with expected future $\psi$ and a component $\pi^{z}$ associated with expected future price markup variations (specified in (6)) . The Smets-Wouters model contains seven exogenous shocks. One of these, $\eta^{p}$, is a price-markup shock and the six others, which we'll collect in a vector $\eta^{\text {other }}$, represent shocks to productivity, interest rates, and so forth. The NKPE makes a strong restriction, that $\eta^{\text {other }}$ affects $\pi$ only through its effect on $\pi^{\psi}$. In contrast, the pricemarkup shock, $\eta^{p}$, affects $\pi$ in two ways: first directly through the effect of $\eta^{p}$ on current and expected future values of $z\left(z_{t}=\left(1-\rho_{p} \mathrm{~L}\right)^{-1}\left(1-\mu_{p} \mathrm{~L}\right) \eta_{t}^{p}\right.$ in the Smets-Wouters DSGE model), and indirectly through the general equilibrium effects of these shocks on current and future values of $\psi$.

Thus, consider a $\eta^{\text {other }}$ shock that leads to an increase in $\pi$. Because this arises through $\pi^{\psi}$, the shock induces a positive correlation between $\pi$ and $\pi^{\psi}$. Indeed, if $\pi$ was affected only by $\eta^{\text {other }}$ shocks, then $\pi_{t}=\pi_{t}^{\psi}$, so that in the forecasting exercises in the last section $\beta_{\psi}(1)=0$ and 
$\beta_{\pi}(1)=1$. Put differently, thinking about $\eta^{\text {other }}$ shocks leads one to the conclusion that an increase in inflation today should predict higher values of $\psi$ in the future $\left(\beta_{\pi}(1)>0\right)$. Yet, as we saw in the last section, just the opposite occurs in the Smets-Wouters model.

The observation that $\beta_{\pi}(1)<0$ therefore leads to two conclusions. First, $\eta^{p}$ must be an important source of variation in both $\pi$ and $\psi$. Second, a shock to $\eta^{p}$ that leads to an increase in inflation must have a persistently negative effect on marginal cost $(\psi)$.

\subsubsection{The structural mechanisms of the Smets-Wouters model}

Using both impulse responses and historical decompositions, we next describe the structural mechanisms that generate this result within the Smets-Wouters model.

First, Figure 10 shows the impulse response functions of a price markup shock within the Smets-Wouters model. Panel A shows the model's implied response of $\pi, z$, and $\psi$ to a price-markup shock $\eta^{p}$. Panel B decomposes this response into the component arising from $\pi^{\psi}$ and $\pi^{z}$. Taking the panels together, this figure shows that a shock to $\eta^{p}$ leads to a relatively short-lived increase inflation that is accompanied by much longer-lived but opposite responses of $\pi_{t}^{\psi}$ and $\pi_{t}^{z}$.

What are the economic mechanisms behind this? We consider a real mechanism and an inflation mechanism: each discussion essentially involves treating the elaborate Smets and Wouters model as if it were one of the first generation DSGE models built around an RBC core (such as in King and Watson (1996), King and Wolman (1996) and Yun (1996)). In this first generation of sticky price DSGE models, there is no trade-off between strict inflation targeting and maintaining output at its natural level (defined as the level of output that arises when there is monopolistic competition and real frictions, but with full nominal price flexibility). These first generation DSGE models generally also specify production functions for which real marginal cost would be well-captured by real unit labor cost.

These models allow us to first think about real activity under a "neutral monetary policy" of strict inflation targeting, in which the effects of nominal stickiness are absent. An increase in the real price markup is like an increase in taxation of output, the proceeds of which are redistributed as transfer payments (monopoly rents) to households. But, in these models, the real price markup $(P / \Psi)$ is just the inverse of real marginal cost $(\psi=\Psi / P)$. The highly 
persistent increase in the price markup $z$ thus must lead to a highly persistent decline in real marginal cost $\psi$. Further, given that the NKPE under strict inflation targeting implies that $\lambda \psi_{t}+$ $z_{t}=0$, a unit increase in $z_{t}$ leads to a $1 / \lambda$ decrease in $\psi_{t}$. Since the real markup shock is highly persistent, there is also a lengthy interval in which the natural rate of output is low due to increases in real distortions.

However, if the monetary authority partly accommodates the markup shock by temporarily raising the inflation target, price stickiness means that the effect of the markup shock on real marginal cost is partially cushioned and there is a smaller fall in output (output rises relative to the depressed natural rate level). In Figure 10, inflation only rises by a small amount (and very temporarily) so that the first-round real analysis of the consequence of the markup shock captures the main effects in a first generation model which had the same inflation response.

We find this pattern intuitive and broadly compatible with the impulse response functions. Yet, the Smets-Wouters model is more elaborate framework (including a different marginal cost measure as well additional real and nominal frictions beyond those in the first generation models), so this can be at best a reference analysis.

Second, Figure 11 uses the historical decomposition approach within the Smets-Wouters model to decompose their measure of $\psi$ into a component associated with price markup shocks (panel A) and all other shocks (panel B). Evidently, the model attributes the trend declines in real unit labor cost (and fundamental inflation) to price markup shocks, which as we saw previously in Figure 7 also explained a good part of the variation in the level of inflation.

The panels of Figure 11 also highlight several major elements of the historical behavior of modified real unit labor cost. Panel A reminds us that the modified real unit labor cost measure displays a downward trend over the 1960-1999 sample period and, as just discussed, most of the fluctuations in that trend are accounted for by the price markup shock. Panel B indicates that wage markup shocks also induce quarter-to-quarter variability in modified real unit labor cost. Panel C indicates that monetary policy shocks play an important role in the rise and fall of modified unit labor cost during the late 1970s and early 1980s, when inflation rose and fell. Finally, Panel D indicates that other factors also induce variability in modified real unit labor cost. 


\section{US inflation and Real Unit Labor Cost 2000-2011}

Thus far we have focused our attention on the 1960-1999 sample period that -- through the work of Gali-Gertler, Sbordone, Smets-Wouters and others -- played a key role in shaping the economics profession's views about the potential of the NKPE for explaining inflation dynamics. In the section, we extend the data through the 2000s to see how the NKPE instructs us to think about inflation during the last decade. This is interesting in its own right and also serves as an out-of-sample external validity check for the in-sample conclusions discussed earlier.

Figure 12 plots real unit labor cost and modified real unit labor cost through 2011:I. While inflation has remained relatively stable over the past decade, both measures of real unit labor cost show significant declines (between 7 and 8 percent from 1999:IV to 2011:I).

Of course, real unit labor cost (in logs, $W-P+n-y$ ) is labor's share of income in the sector: the stability of this "great ratio" is one of the standard stylized facts of macroeconomics. From a New Keynesian modeling perspective, the constancy is a production function attribute governing low frequency real reactions, but is overlaid by cyclical variations in $\psi=W+n-P$ $-y$ arising from the interplay of imperfect competition, sticky prices, and shocks. Over the benchmark sample period, 1960-1999, the average value of labor share in the non-farm business sector was $63.8 \%$, while it was $65.1 \%$ in 1960.1 and $62.6 \%$ in 1999.4. In the last quarter of our data set, 2011.1, it had fallen to $57.8 \%$. The source of this decline in labor's share (real unit labor cost) is both puzzling and important. ${ }^{21}$

However, in the context of the NKPE the puzzle about labor's share is not its source, but rather its predicted effect on inflation. Figure 13 plots inflation together with measures of fundamental inflation computed using the GG-VAR and Smets-Wouters-DSGE models extended with data through 2011:I. Evidently the large declines in real unit labor cost translate into large declines in fundamental inflation. While actual inflation is essentially unchanged over the post-1999 period, the measure of fundamental inflation constructed along Gali-Gertler lines fell by nearly 15 percent and that implied by the Smets-Wouters DSGE model fell by nearly 20 percent. That is, both measures of fundamental inflation predicted large deflation over the last decade.

\footnotetext{
${ }^{21}$ The decline in labor's share is discussed, inter alia, in Fleck et al (2011).
} 
Our interpretation of this evidence is that real unit labor cost has exhibited important low-frequency variation that is unrelated to inflation. The last decade provides a dramatic example of this lack of comovement. However, our earlier analysis using the Smets-Wouters modified real unit labor cost suggests that the pattern of limited low frequency comovement also arose in the earlier sample period (1960-1999) and played out through the Smets and Wouters DSGE model in its estimation period. In this sense, their model was forced to deal with this low-frequency variability in the earlier sample period, and as we discussed above, the model did this by using the price-markup shock to (essentially) explain the trend real unit labor cost. Of course, given the structure of their model, any low-frequency variability in real unit labor cost must be intimately related to variability in inflation, so the same shocks the explained the trends in real unit labor cost (the price-markup shock) must also explain some of the variation in inflation (see Figure 7, panel A).

Figure 14 decomposes our SW fundamental inflation measure over the extended sample period into a component associated with the model's price markup shocks and with all of the other shocks in the model. Given the analysis in the last section, it is not surprising that the price markup shocks explain the trend in fundamental inflation. However, it is interesting to note that the "detrended" version of fundamental inflation (that is, the component of fundamental inflation associated with shocks other than the price-markup shock) fits inflation much like our Gali-Gertler measure did over the 1960-1999 sample period. However, this component explains little of the variation in inflation since about 1985 , following the disinflation of the early 1980 s.

\section{Conclusions}

An earlier generation of Keynesian macroeconometric models developed in the $1960 \mathrm{~s}$ featured price and wage sectors that fit well during estimation periods, but that subsequently foundered on episodes of stagflation and the implication that there was an important long-run trade-off between inflation and unemployment. The Lucas critique led to an abandonment of these models by academics, a deepened skepticism about them within parts of the monetary policy community, and a search for macroeconomic models with stronger microeconomic foundations and better empirical performance. 
The microeconomic pricing foundations developed along New Keynesian lines incorporate expectations mechanisms which produce a shifting trade-off between inflation and real activity. They stressed the role of marginal cost in pricing and inflation dynamics, focusing on real unit labor costs as a proxy for marginal cost, and thereby avoided the thorny issue of measuring capacity output. Estimated over the mid 1960s through the early 2000s, these models provide an interpretation of the interval of rising inflation in the late 1960s and early 1970s, the subsequent stagflation episodes, the Volcker disinflation, and the Great Moderation beginning in the mid 1980s. The single equation studies of Gali and Gertler (1999) and Sbordone (2002) that popularized the New Keynesian Pricing Equation had three important properties that we display via replication and decompositions: a minor role of a transitory variation in marginal cost, a major role for expected of inflation, and an associated major role for a measure of expected future variations in marginal cost as captured by the construction of "fundamental inflation." We show that the DSGE model of Smets and Wouters (2007), which contains a variant of the New Keynesian Pricing Equation, has the first two of these properties but is problematic along the third dimension: actual inflation and our SW fundamental inflation construction behave very differently. We trace this finding to the measure of real unit labor cost employed by Smets and Wouters (2007) which has a major downward trend so that their structural model is forced to include a major upward trend in a measure of price markup shocks. We considered how these structural markup shocks likely operate within the Smets-Wouters DSGE model, describing consequences for both real activity and inflation.

Looking beyond the estimation period of the single equation studies and of the canonical DSGE model, we find that all measures of real unit labor costs display major downward trends that not accompanied by similar trends in inflation. (Equivalently, labor's share has fallen dramatically since the late 1990s, while there has been little variation in inflation). While it is possible to reconcile this absence of comovement by the introduction of large price markup shocks that are negatively correlated with real unit labor cost, we find it more plausible that real factors are influencing labor's share in ways that are largely unrelated to inflation. Tracing the sources of these changes and their implications for specification of pricing equations look to be first-order topics for macroeconomic research.

Our work also illustrates a strategy which we believe will be an essential component of productive work with DSGE models, namely the detailed examination of a single structural 
equation or block of equations within using limited and full information from the complete model. The earlier generation of Keynesian macropolicy models were built by fitting together blocks of equations, whose performance was carefully scrutinized by the economists constructing these specifications. The builders of such earlier models were appropriately criticized in the late 1970s--by Robert Lucas, Thomas Sargent, Christopher Sims, John Taylor and others - for not paying sufficient attention to general equilibrium, including the consistency of behavioral specifications and the rationality of expectations. These critiques provided a major impetus for the development of modern DSGE models, including the now standard toolkit of linear rational expectations econometrics. Yet, DSGE modeling practice places nearly complete weight on exploration of system properties including measures of fit and forecasting performance, impulse response and moment analysis, and historical decompositions. With a focus on system properties alone, features that are important for central model components - such as the evolving joint behavior of inflation and real unit labor costs - are less likely to be recognized as central. However, detailed analysis of the structural inflation equation, as we have undertaken, makes imperfect specification more transparent. More generally, detailed exploration of equations and system blocks will lead to better DSGE model construction. 


\section{References}

An, Sungbae and Frank Schorfheide. 2007. "Bayesian Analysis of DSGE Models," Econometric Reviews, 26 (2-4): 113-172.

Calvo, Guillermo. 1983. "Staggered prices in a utility-maximizing framework," Journal of Monetary Economics, 12 (3): 383-398

Campbell, John Y., and Robert J. Shiller. 1987. "Cointegration and tests of present value models," Journal of Political Economy, 95(5): 1062-1088.

Christiano, Lawrence J., Martin Eichenbaum, and Charles L. Evans. 1997. "Sticky price and limited participation models of money: A comparison," European Economic Review, 41(6): 1201-1249.

Christiano, Lawrence J., Martin Eichenbaum, and Charles L. Evans. 2005. "Nominal Rigidities and the Dynamic Effects of a Shock to Monetary Policy," Journal of Political Economy, 113(1): 1-45.

Collard, Fabrice and Harris Dellas. 2006. "Dissecting the New Keynesian Model," available at http://harrisdellas.net/research.html

Eckstein, Otto and Gary Fromm. 1968. "The Price Equation,” American Economic Review, 58 (5): 1159-1183.

Eichenbaum, Martin and Jonas D.M. Fisher. 2007. "Estimating the frequency of price reoptimization in Calvo-style models," Journal of Monetary Economics, 54(7): 20322047.

Edge, Rochelle and Refet Gürkaynak. 2010. "How Useful are Estimatted DSGE Model Forecasts for Central Bankers?," Brookings Papers on Economic Activity, Fall 2010: 209-244.

Erceg, Christopher J., Dale Henderson, and Andrew T. Levin. 2000. “Optimal monetary policy with staggered wage and price contracts," Journal of Monetary Economics, 46(2): 281313.

Fleck, Susan, John Glaser, and Shawn Sprague. 2011. "The compensation-productivity gap: a visual essay," Monthly Labor Review, January 2011: 57-69.

Fuhrer, Jeffrey C. 1997. "The (Un)Importance of Forward-Looking Behavior in Price Specifications," Journal of Money, Credit, and Banking, 29: 338-350. 
Gali, Jordi, and Mark Gertler. 1999. "Inflation Dynamics: A Structural Econometric Analysis," Journal of Monetary Economics, 44(2): 195-222.

Gali, Jordi 2008. Monetary Policy, Inflation, and the Business Cycle, Princeton University Press, Princeton, NJ.

Goodfriend, Marvin and Robert G. King. 1997. "The New Neoclassical Synthesis and the Role of Monetary Policy.” In B. Bernanke and J. Rotemberg, eds., National Bureau of Economic Research Macroeconomics Annual 1997, Cambridge: MIT Press: 231-95.

Hodrick, Robert, and Edward C. Prescott. 1997. "Postwar U.S. Business Cycles: An Empirical Investigation," Journal of Money, Credit, and Banking, 29 (1): 1-16.

Kimball, Miles S. 1995. "The Quantitative Analytics of the Basic Neomonetarist Model," Journal of Money, Credit, and Banking, 27(4):1241-77.

King, Robert G. and Mark W. Watson. 1996. "Money, Prices Interest Rates and the Business Cycle," Review of Economics and Statistics, Vol. LXXVIII, Number 1: 35-53.

King, Robert G. and Alexander L. Wolman. 1996. "Inflation Targeting in a St. Louis Model of the 21st Century," Federal Reserve Bank of St. Louis Review, 78(3) May/June 1996): 83-107.

Kurmann, Andre. 2005. "Quantifying the Uncertainty about a Forward-Looking New Keynesian Pricing Model,” Journal of Monetary Economics, 52(6): 1119-1134.

Nelson, Charles R and William G. Schwert. "Short-Term Interest Rates as Predictors of Inflation: On Testing the Hypothesis That the Real Rate of Interest is Constant," American Economic Review, 67(3): 478-86.

Roberts, John M. 1995. “New Keynesian Economics and the Phillips Curve,” Journal of Money, Credit and Banking, 27(1) part 1: 975-984.

Sbordone, Argia. 2002. "Prices and Unit Labor Costs: A New Test of Price Stickiness," Journal of Monetary Economics 49 (2): 265-291.

Smets, Frank, and Raf Wouters. 2003. “An Estimated Dynamic Stochastic General Equilibrium Model of the Euro Area," Journal of the European Economic Association, 1(5): 112375.

Smets, Frank, and Rafael Wouters. 2007. "Shocks and Frictions in US Business Cycles: A Bayesian DSGE Approach," American Economic Review, 97(3): 586-606. 
Stock, James H. 1991. "Confidence Intervals for the Largest Autoregressive Root in U.S. Economic Time Series," Journal of Monetary Economics, 28: 435-460.

Stock, James H. and Mark W. Watson. 1999. "Forecasting Inflation,” Journal of Monetary Economics, 44(2): 293-335.

Stock, James H. and Mark W. Watson. 2007. "Why Has U.S. Inflation Become Harder to Forecast?," Journal of Money, Banking and Credit, 39(1): 3-33.

Taylor, John B. 1993. “Discretion versus policy rules in practice," Journal of Monetary Economics, Carnegie-Rochester Conference Series on Public Policy, 39: 195-214.

Walsh, Carl E. 2010. Monetary Theory and Policy, MIT Press, Cambridge, MA.

Woodford, MIchael. 2003, Interest and Prices: Foundations of a Theory of Monetary Policy, Princeton University Press, Princeton, NJ.

Yun, Tack. 1996. "Nominal Price Rigidity, Money Supply Endogeneity, and Business Cycles," Journal of Monetary Economics, 37(2): 345-70. 
All data are from FRED (Federal Reserve Bank of St. Louis). The table below documents the data series used in our analysis.

Table A.1

\begin{tabular}{|c|c|c|c|}
\hline Series & FRED Label & Desc & Units \\
\hline \multicolumn{4}{|c|}{ Prices } \\
\hline GDP deflator & GDPCTPI & Gross Domestic Product: Chain-type Price Index & $\begin{array}{l}\text { Index } \\
2005=100\end{array}$ \\
\hline $\begin{array}{l}\text { NFB Output } \\
\text { deflator }\end{array}$ & IPDNBS & Nonfarm Business Sector: Implicit Price Deflator & $\begin{array}{l}\text { Index } \\
2005=100\end{array}$ \\
\hline \multicolumn{4}{|c|}{ Employment } \\
\hline $\begin{array}{l}\text { Household survey } \\
\text { employment }\end{array}$ & CE160V & Civilian Employment & Thousands \\
\hline $\begin{array}{l}\text { Employment NFB } \\
\text { sector }\end{array}$ & PRS85006013 & Nonfarm Business Sector: Employment & $\begin{array}{l}\text { Index } \\
2005=100\end{array}$ \\
\hline $\begin{array}{l}\text { Population (16 } \\
\text { and over) }\end{array}$ & CNP16OV & $\begin{array}{l}\text { Civilian Noninstitutional Population (16 and older) } \\
\text { : Note CNP16OV is a non-revised series that } \\
\text { contains jumps, etc. We have eliminated outliers } \\
\text { in growth rates and fitted cubic spline to monthly } \\
\text { growth rates, then used this to get adjusted } \\
\text { monthly levels, which were temporally } \\
\text { aggregated to quarterly series. }\end{array}$ & Thousands \\
\hline Total Hours NFB & HOANBS & Nonfarm Business Sector: Hours of All Persons & $\begin{array}{l}\text { Index } \\
2005=100\end{array}$ \\
\hline $\begin{array}{l}\text { Avg. Weekly } \\
\text { Hours NFB }\end{array}$ & PRS85006023 & Nonfarm Business Sector: Average Weekly Hours & $\begin{array}{l}\text { Index } \\
2005=100\end{array}$ \\
\hline \multicolumn{4}{|c|}{ Wages } \\
\hline $\begin{array}{l}\text { Compensation } \\
\text { per hour NFB } \\
\text { sector - Nominal }\end{array}$ & COMPNFB & $\begin{array}{l}\text { Nonfarm Business Sector: Compensation Per } \\
\text { Hour }\end{array}$ & $\begin{array}{l}\text { Index }(2005= \\
100)\end{array}$ \\
\hline \multicolumn{4}{|c|}{ Output, Consumption, and Investment } \\
\hline Real GDP & GDPC96 & Real Gross Domestic Product, 3 Decimal & $\begin{array}{l}\text { Billions of } \\
\text { Chained } \\
2005 \text { Dollars }\end{array}$ \\
\hline Real Output NFB & OUTNFB & Nonfarm Business Sector: Output & $\begin{array}{l}\text { Index } \\
2005=100\end{array}$ \\
\hline $\begin{array}{l}\text { Investment - } \\
\text { Nominal }\end{array}$ & GPDI & Gross Private Domestic Investment & $\begin{array}{l}\text { Billions of } \\
\text { Dollars }\end{array}$ \\
\hline $\begin{array}{l}\text { Consumption - } \\
\text { Nominal }\end{array}$ & PCEC & Personal Consumption Expenditures & $\begin{array}{l}\text { Billions of } \\
\text { Dollars }\end{array}$ \\
\hline \multicolumn{4}{|c|}{ Interest Rates } \\
\hline Fed Funds Rate & FEDFUNDS & Effective Federal Funds Rate & $\begin{array}{l}\text { Percentage } \\
\text { points }\end{array}$ \\
\hline
\end{tabular}


These data were used to construct two measures of real unit labor cost:

- The Gali-Gertler measure of log-real unit cost is $\psi^{G G}=\ln \left(\frac{C O M P N F B \times H O A N B S}{I P D N B S \times O U T N F B}\right)$.

- The Smets-Wouters measure of modified real unit labor cost is given by

$$
\psi^{S W}=\left[\ln \left(\frac{C O M P N F B}{G D P C T P I}\right)-\bar{\gamma} t\right]+\ln \left(\frac{P R S 85006023 \times C E 16 O V}{C N P 160 V^{a}}\right)-\Phi^{-1}\left[\ln \left(\frac{G D P C 96}{C N P 160 V^{a}}\right)-\bar{\gamma} t\right]
$$

where $C N P 160 V^{a}$ is the adjusted value of population given in Table A.1, and $\bar{\gamma}$ and $\Phi$ are parameters estimated by Smets-Wouters $(\bar{\gamma}=0.00432$ and $\Phi=1.614980$.)

The data were also used to construct the seven variables used in the Smets-Wouters DSGE model. Using the notation in their equation (15), the variables are:

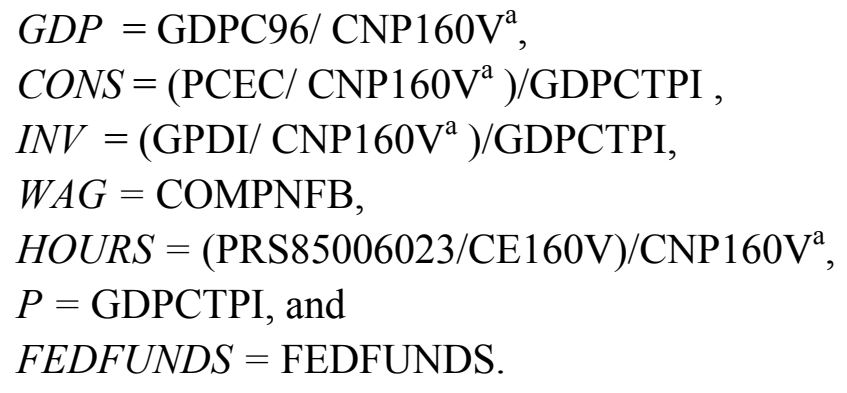


Table 1: NKPE Parameter Values

\begin{tabular}{|c|c|c|c|c|c|c|c|}
\hline & \multicolumn{3}{|c|}{ Parameters in equation (2) } & \multicolumn{4}{c|}{ Parameters in equation (3) } \\
\hline Model & $\gamma_{b}$ & $\gamma_{f}$ & $\lambda$ & $\rho$ & $\delta$ & $\lambda_{\psi}$ & $\lambda_{z}$ \\
\hline $\begin{array}{c}\text { Gali- } \\
\text { Gertler }\end{array}$ & 0.253 & 0.682 & 0.153 & 0.325 & 0.876 & 0.197 & 5.138 \\
\hline $\begin{array}{c}\text { Smets- } \\
\text { Wouters }\end{array}$ & 0.186 & 0.813 & 0.082 & 0.228 & 0.998 & 0.101 & 4.911 \\
\hline
\end{tabular}

Notes: Gali-Gertler parameter values are from Gali and Gertler (1999, Table 2, Row 1). Smets-Wouters structural parameter values are from Smets and Wouters (2007, Table 1A) and the Dynare replication files for this paper, which are then used to calculate the parameters in equation (6). The values of $\lambda, \lambda_{\psi}$, and $\lambda_{z}$ reported above are four times the values reported in Gali-Gertler and Smets-Wouters because we measure inflation at annual rate. 
Table 2: Properties of Fundamental Inflation Using Different Parameters, Forecasting Rules, and Unit Labor Cost Measures

\begin{tabular}{|c|c|c|c|c|c|c|c|c|}
\hline Row & $\theta$ & M & $\psi$ & $\beta_{\psi}(1)$ & $\beta_{\pi}(1)$ & $\sigma\left(\tilde{\pi}^{\psi}\right)$ & $\operatorname{cor}\left(\pi^{\psi}, \tilde{\pi}^{\psi}\right)$ & $\operatorname{cor}\left(\pi, \tilde{\pi}^{\psi}\right)$ \\
\hline \multicolumn{9}{|c|}{ A. VAR-Based Measures of Fundamental Inflation } \\
\hline 1 & GG & $M^{G G-V A R}$ & $\psi^{G G}$ & 1.30 & 0.26 & 2.90 & 0.99 & 0.61 \\
\hline 2 & SW & $M^{G G-V A R}$ & $\psi^{G G}$ & 1.09 & 0.99 & 3.94 & 0.99 & 0.87 \\
\hline 3 & GG & $M^{G G-V A R}$ & $\psi^{S W}$ & 1.30 & 0.26 & 4.31 & 1.00 & 0.51 \\
\hline 4 & GG & $M^{S W-V A R}$ & $\psi^{S W}$ & 2.12 & -0.29 & 6.31 & 1.00 & 0.28 \\
\hline 5 & SW & $M^{-S W-V A R}$ & $\psi^{S W}$ & 4.37 & -2.11 & 12.45 & 1.00 & -0.01 \\
\hline \multicolumn{9}{|c|}{ B. DSGE-Based Measures of Fundamental Inflation } \\
\hline 6 & SW & $M^{S W}$ & $\psi^{S W}$ & 1.89 & -0.89 & 5.22 & 0.97 & 0.02 \\
\hline 7 & GG & $M^{S W}$ & $\psi^{S W}$ & 1.63 & -0.34 & 4.63 & 0.99 & 0.24 \\
\hline 8 & SW & $M^{S W}$ & $\psi^{G G}$ & 1.89 & -0.89 & 3.46 & NA & -0.15 \\
\hline 9 & GG & $M^{S W}$ & $\psi^{G G}$ & 1.63 & -0.34 & 3.01 & NA & 0.20 \\
\hline
\end{tabular}

Notes: $\theta^{G G}$ are the Gali-Gertler parameter values shown in Table 1; $\theta^{S W}$ are the corresponding Smets-Wouters values. $M^{G G-V A R}$ are VAR coefficients estimated from a bivariate $\left(\pi, \psi^{G G}\right)$ VAR(4) model over 1960:I-1999:IV; $M^{S W-V A R}$ are VAR coefficients estimated from a bivariate $\left(\pi, \psi^{S W}\right)$ VAR(4) model over 1960:I-1999:IV; and $M^{S W}$ is the companion matrix from the SmetsWouters DSGE model. $\psi^{G G}$ is the logarithm of real unit labor cost for the non-farm business sector and $\psi^{S W}$ is the Smets-Wouters modified real unit labor cost measure. See Figure 8 for a visual comparison of the two series. 
Figure 1: Gali and Gertler Data

Inflation and Real Unit Labor Cost

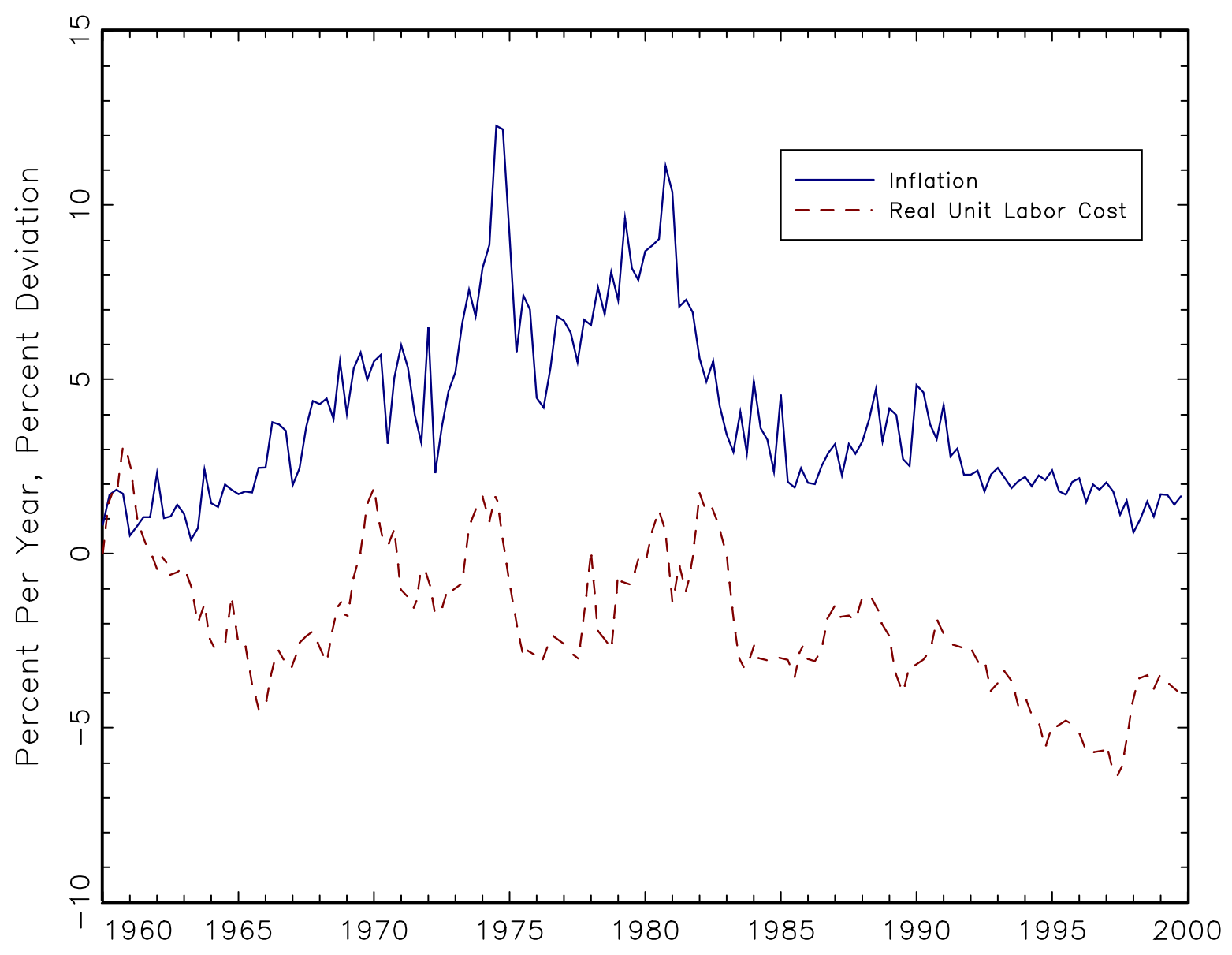

Notes: The solid line is inflation in the GDP price deflator measured in percentage points at an annual rate; that is, $400 \times \ln \left(P_{t} / P_{t-1}\right)$, where $P_{t}$ is the value of the GDP deflator. The dashed line is the deviation in real unit labor cost from its value in 1960:I in percentage points; that is, 100× $\left(\psi_{t}^{G G}-\psi_{1960: I}^{G G}\right)$, where $\psi^{G G}$ is the logarithm of the index of real unit labor cost in the non-farm business sector (see Appendix A). 
Figure 2: GG inflation breakdown into 4 components
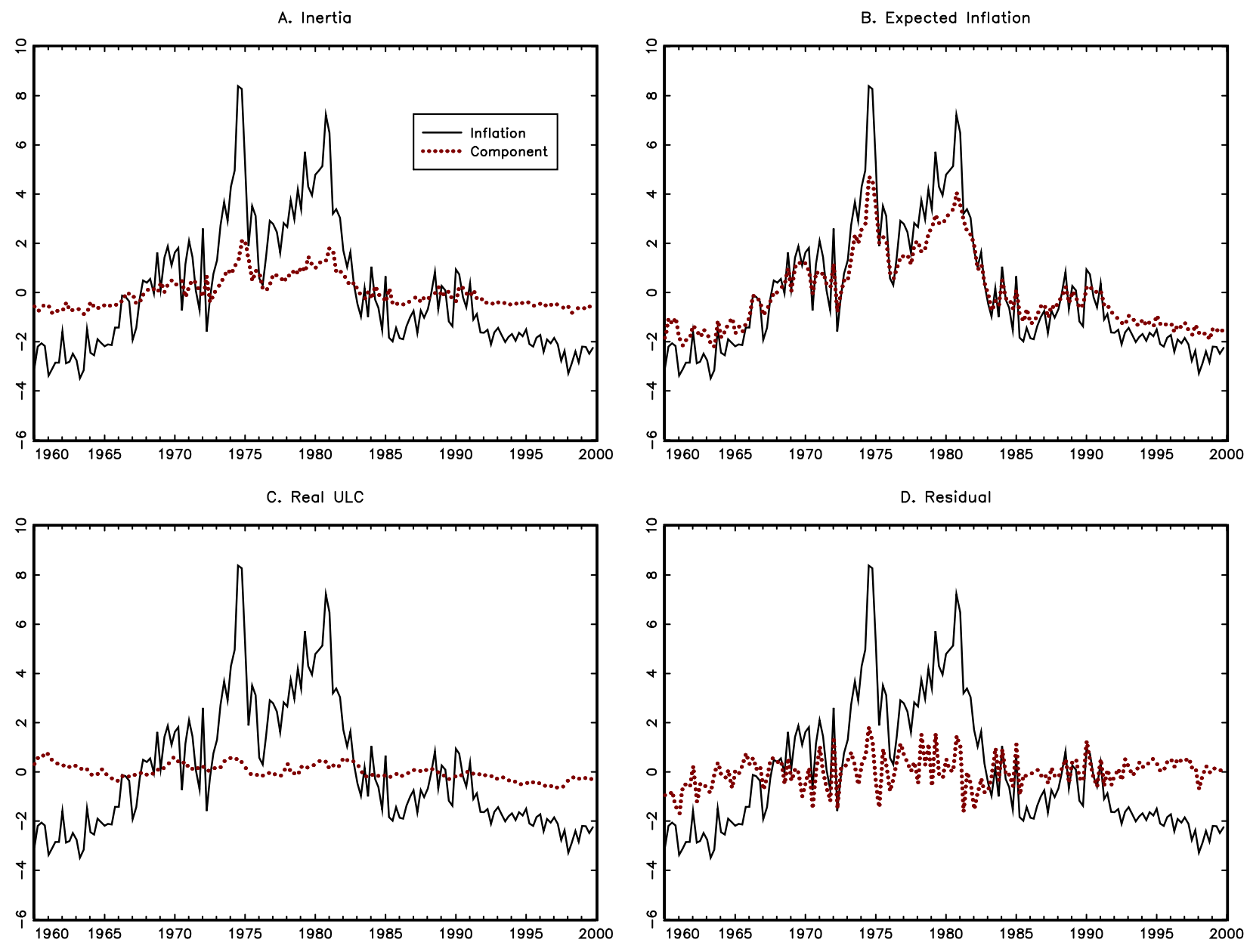

Notes: The solid line in each figure is inflation shown in Figure 1. The dotted lines are the components of decomposition 1 (see equation [2]): (a) inertia $\left(\gamma_{b} \pi_{t-1}\right)$; (b) expectations $\left(\gamma_{f}\right.$ $\left.E_{t} \pi_{t+1}\right)$; (c) real ulc $\left(\lambda \psi_{t}\right)$; and (d) residual $\left(z_{i}\right)$. The parameter values $\gamma_{b}, \gamma_{f}$, and $\lambda$ are from GaliGertler and given in Table 1 of this paper. Real unit labor cost, $\psi$, is from Figure 1. Expected inflation, $E_{t} \pi_{t+1}$, is computed from a bivariate $\operatorname{VAR}(4)$ that includes $\pi$ and $\psi$. 
Figure 3: GG Fundamental Inflation

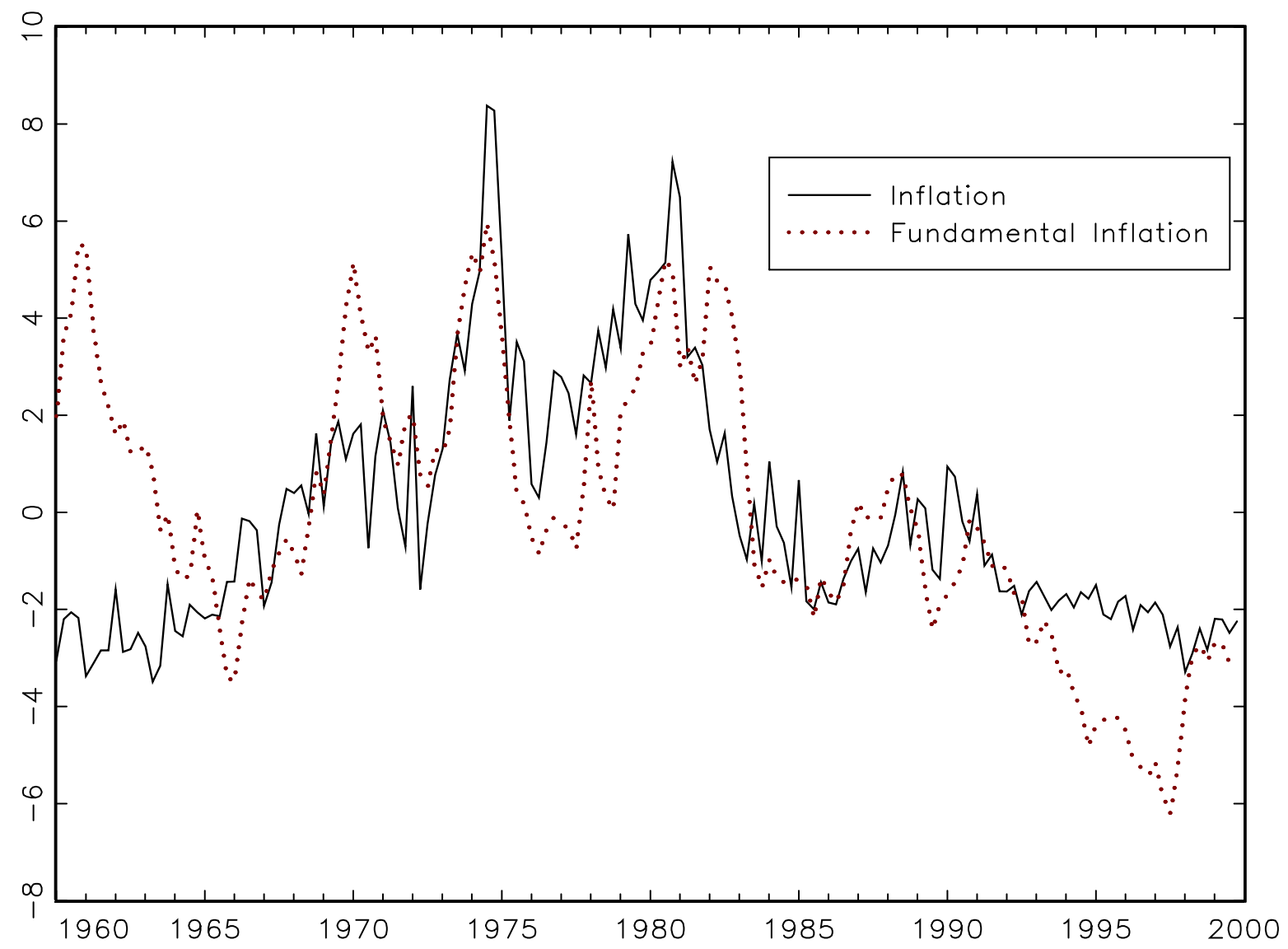

Notes: The solid line is inflation shown in Figure 1. The dotted line is fundamental inflation $\pi_{t}^{\psi}$ from equation (5). The parameter values $\gamma_{b}, \gamma_{f}$, and $\lambda$ are from Gali-Gertler and given in Table 1 of this paper. Real unit labor cost, $\psi$, is from Figure 1. Expected real unit labor cost, $E_{t} \psi_{t+j}$, is computed from a bivariate $\operatorname{VAR}(4)$ that includes $\pi$ and $\psi$. 
Figure 4: Smets-Wouters Data

Inflation and Modified Real Unit Labor Cost

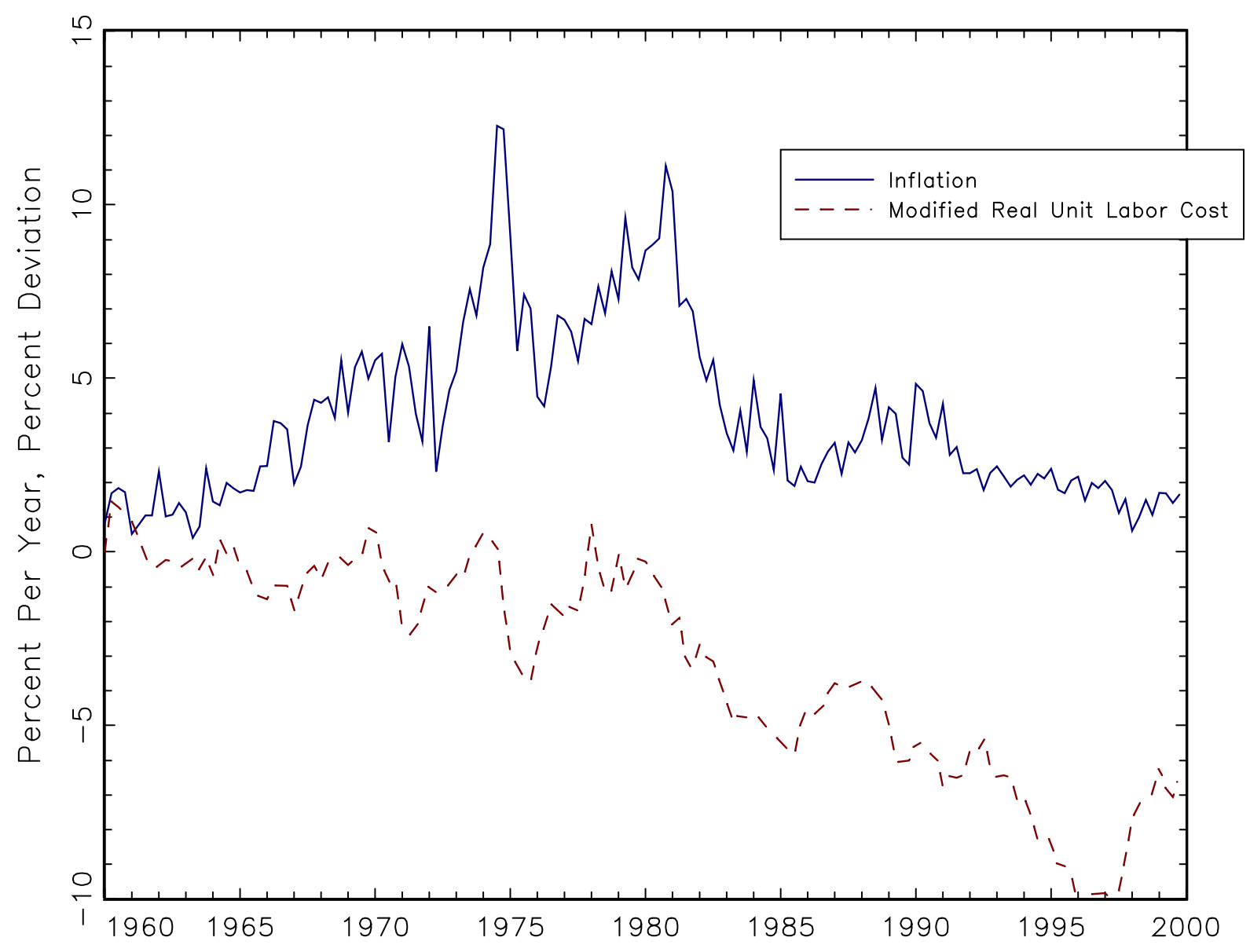

Notes: The solid line is inflation shown in Figure 1. The dashed line is the deviation of modified real unit labor cost (see equation (8) and Appendix A) from its value in 1960:I in percentage points; that is, $100 \times\left(\psi_{t}^{S W}-\psi_{1960: I}^{S W}\right)$, where $\psi^{S W}$ is the modified unit labor cost measure developed by Smets and Wouters (see Appendix A). 
Figure 5: Historical Decomposition of Inflation in the Smets-Wouters DSGE Model

A. Price Markup Shock
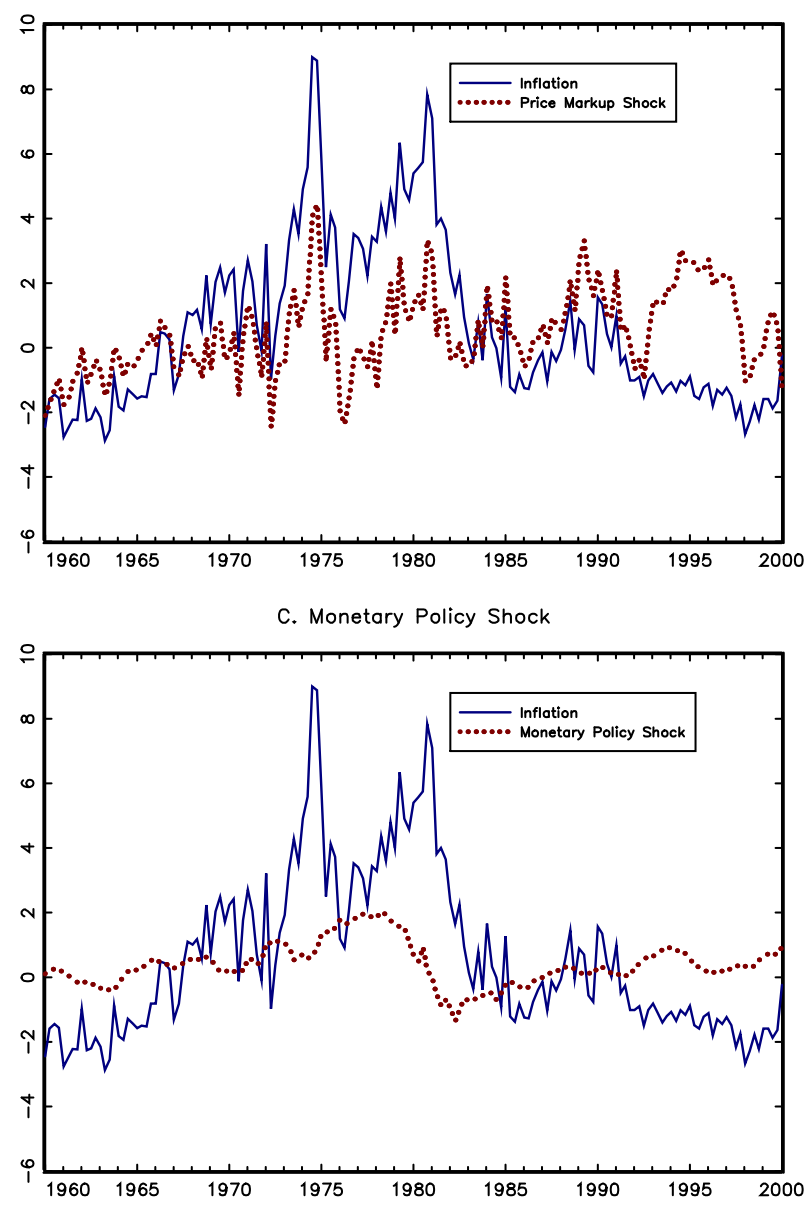

B. Wage Markup Shock
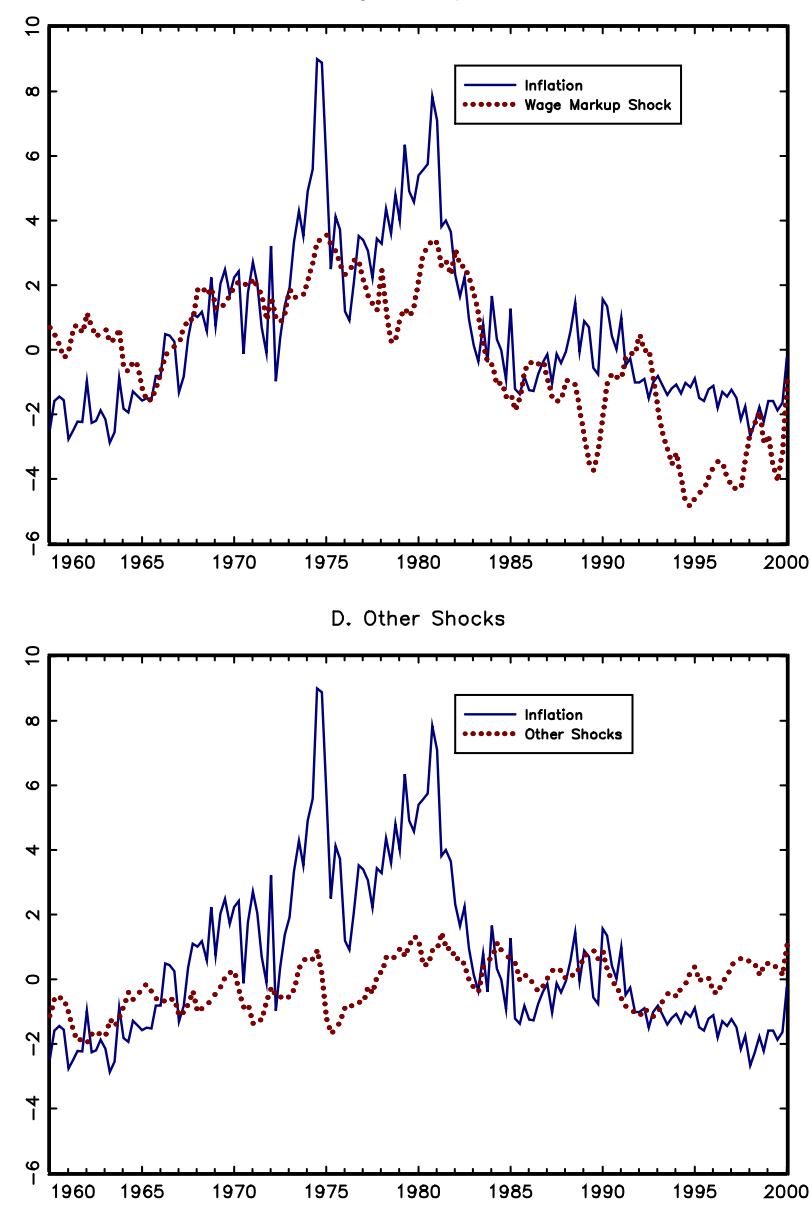

Notes: The solid line is inflation shown in Figure 1, normalized to have a mean of zero over the Smets-Wouters sample period. The dotted lines are the components of inflation attributed to (a) price markup shocks; (b) wage markup shocks; (c) monetary policy shocks; and (d) all other shocks, where these shocks and contributions are computed using the Smets and Wouters DSGE model evaluated at the posterior mean of the model's parameters. 
Figure 6: SW inflation breakdown into 4 components

A. Inertia

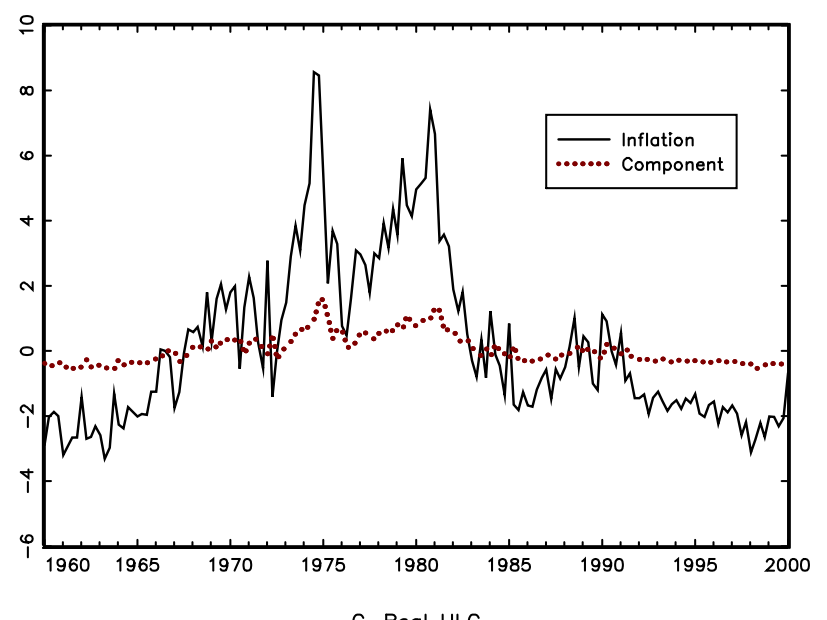

C. Real ULC

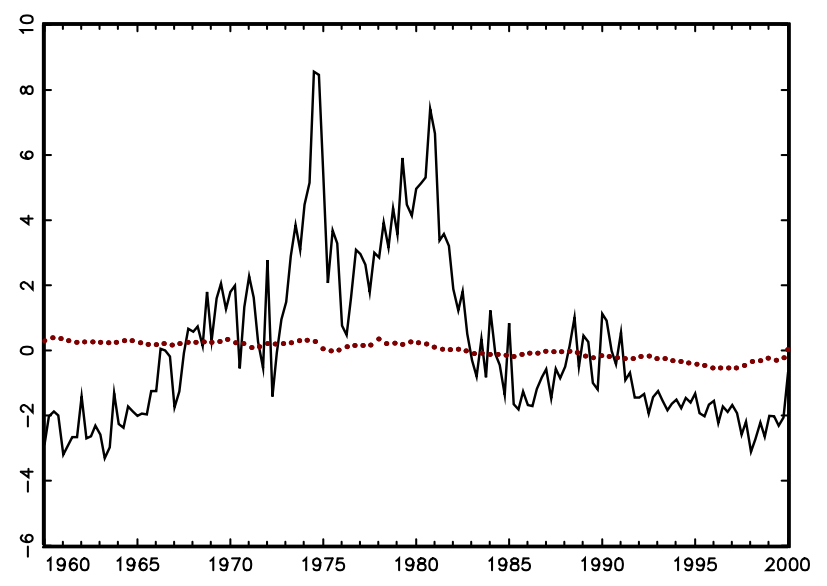

B. Expected Inflation

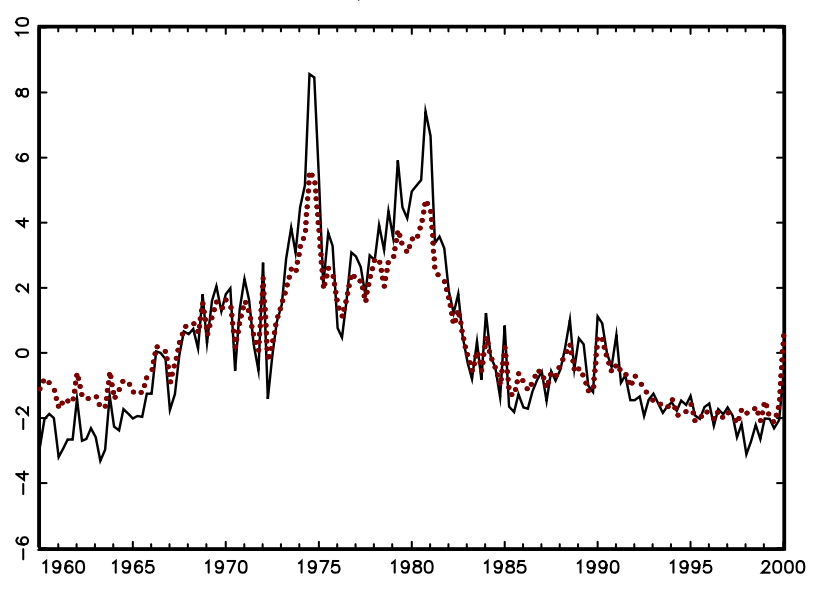

D. Residual

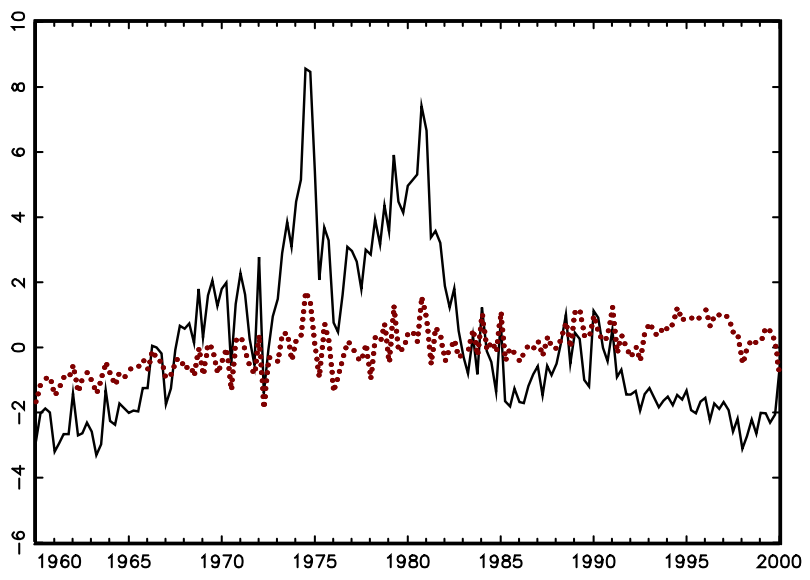

Notes: The solid line in each figure is inflation shown in Figure 1. The dotted lines are the components of decomposition 1 (see equation [2]): (a) inertia $\left(\gamma_{b} \pi_{t-1}\right)$; (b) expectations ( $\gamma_{f}$ $\left.E_{t} \pi_{t+1}\right)$; (c) real ulc $\left(\lambda \psi_{t}\right)$; and (d) residual $\left(z_{i}\right)$. The parameter values $\gamma_{b}, \gamma_{f}$, and $\lambda$ are from Smets-Wouters and given in Table 1 of this paper. Real unit labor cost, $\psi$, is from figure 4. Expected inflation, $E_{t} \pi_{t+1}$, is computed from the Smets and Wouters DSGE model. 
Figure 7: SW Fundamental Inflation

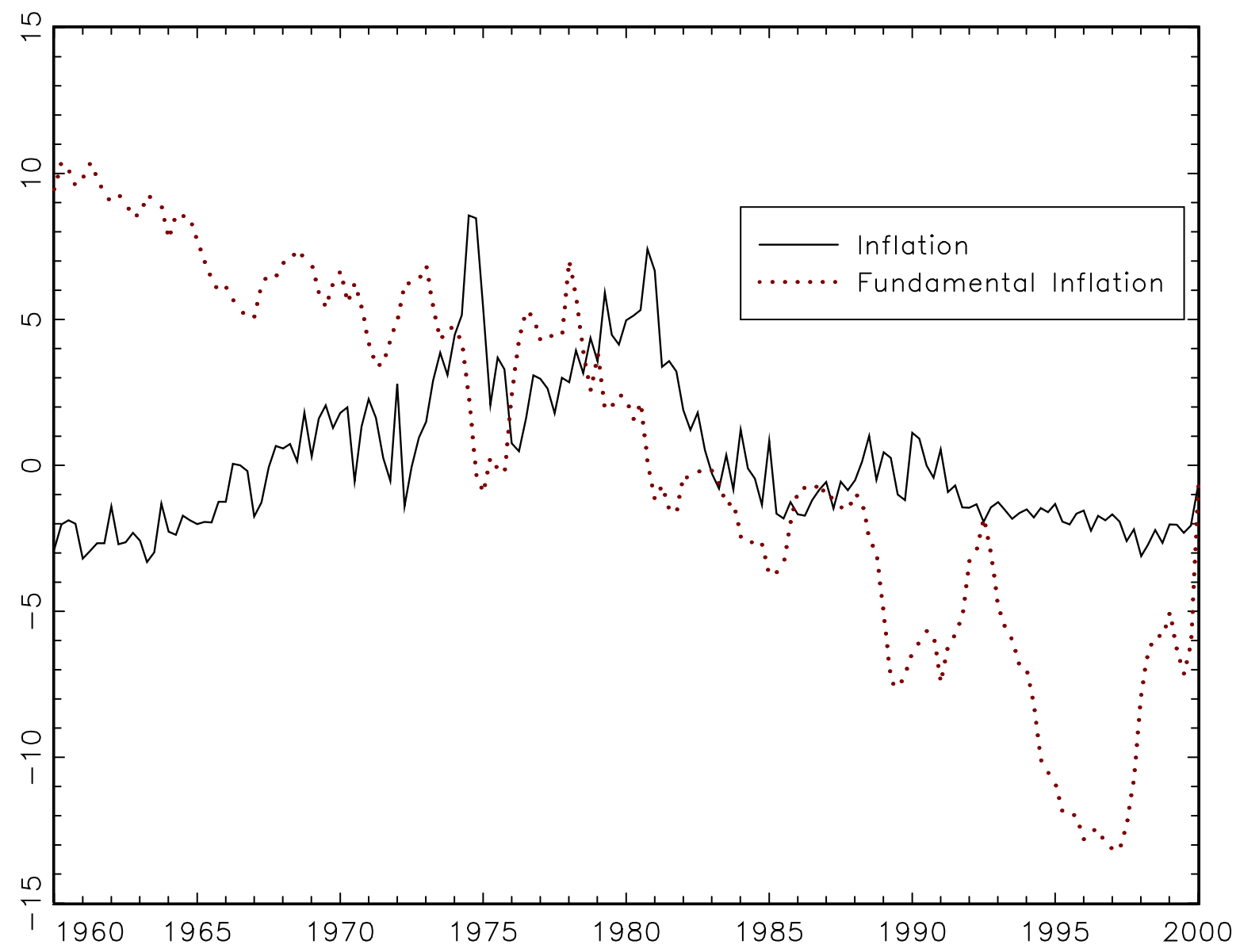

Notes: The solid line is inflation shown in Figure 1. The dotted line is fundamental inflation, $\pi_{t}^{\psi}$, from equation (5). The parameter values $\gamma_{b}, \gamma_{f}$, and $\lambda$ are from Smet-Wouters and are given in Table 1 of this paper. Real unit labor cost, $\psi$, is from Figure 4. Expected real unit labor cost, $E_{t} \psi_{t+j}$, is computed from the Smets and Wouters DSGE model. 
Figure 8:

Comparison of Gali-Gertler and Smets-Wouters Measures of Real Unit Labor Cost

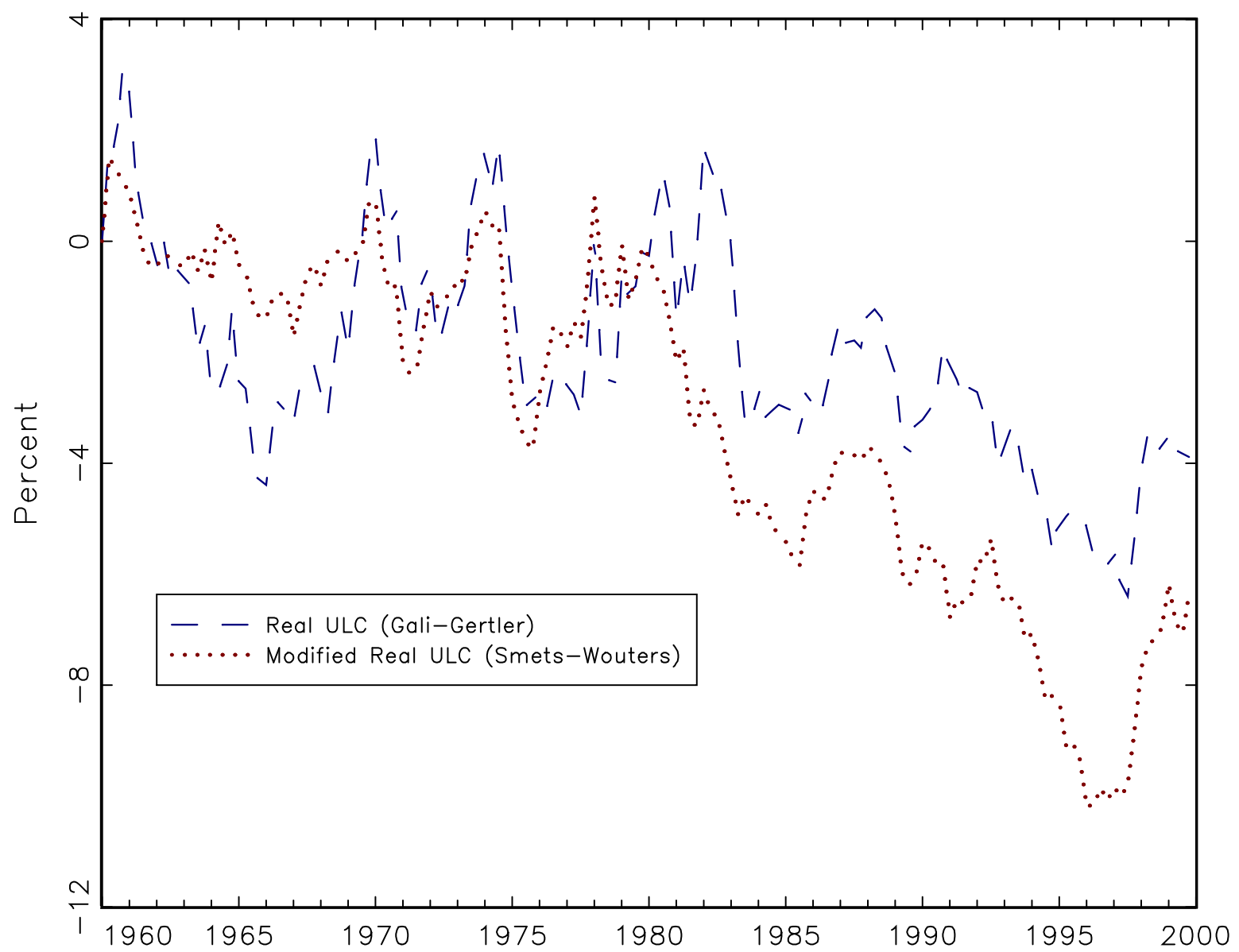

Notes: The figures shows the values of real unit labor and modified real unit labor cost from Figures 1 and 4. 


\section{Figure 9: Fundamental Inflation and Its Approximation}

A. GG Data

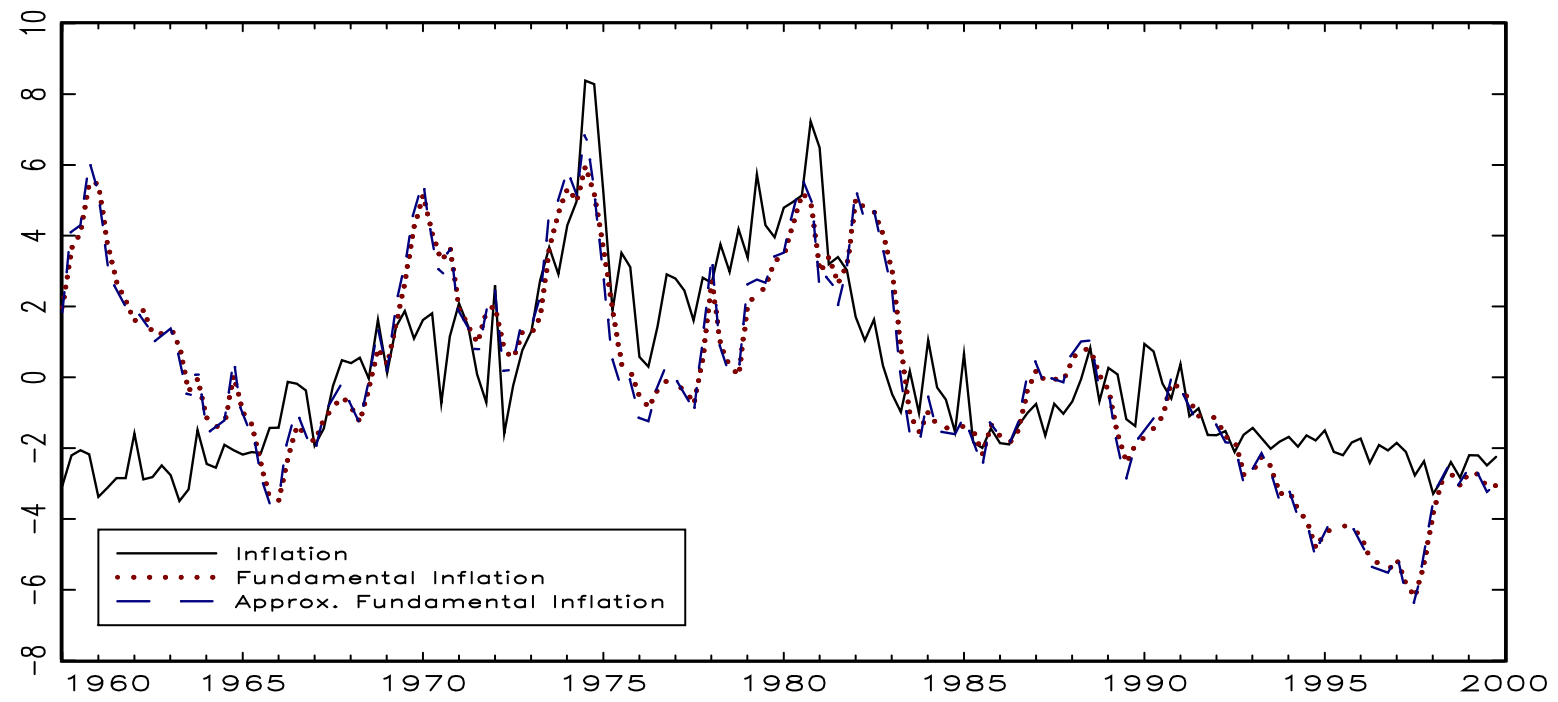

B. SW Data

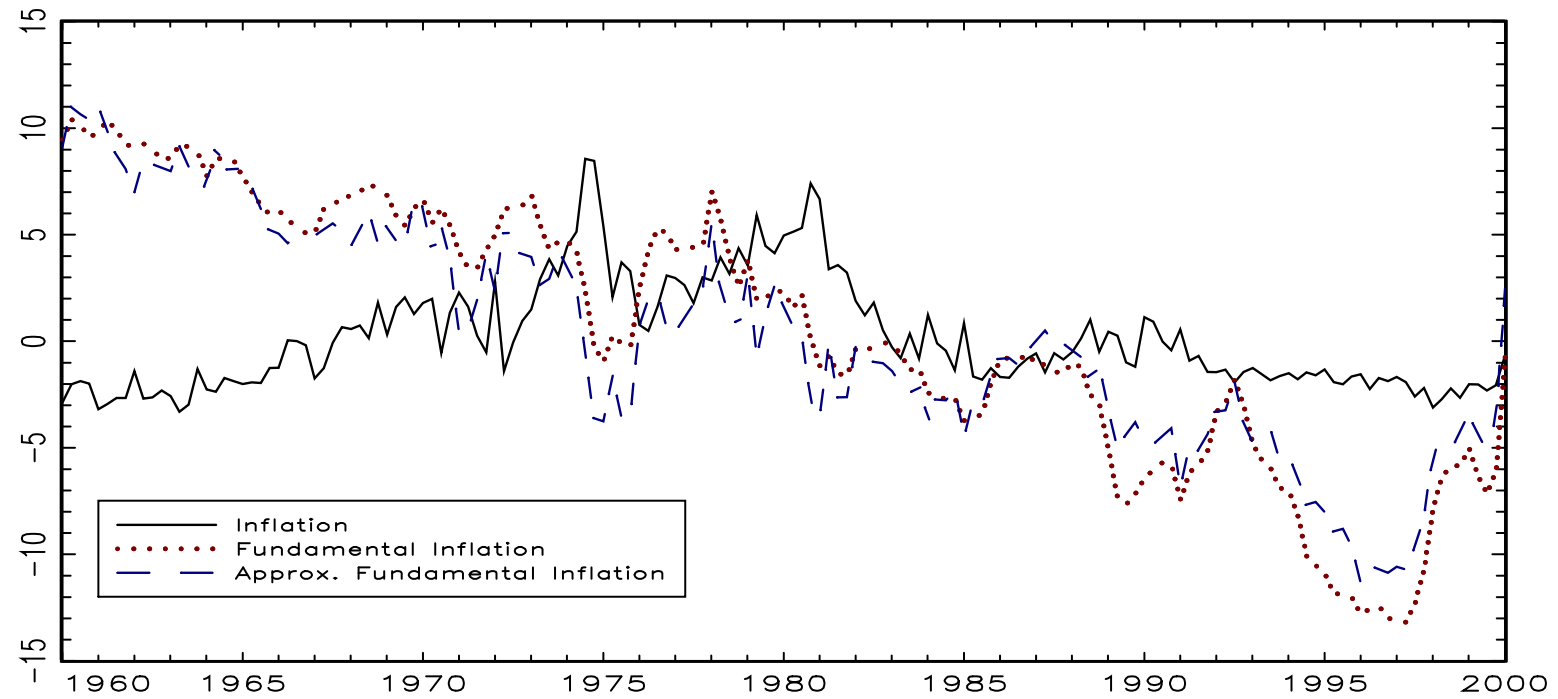

Notes: Each panel shows inflation and fundamental inflation (from Figures 3 and 7) together with the approximation to fundamental inflation discussed in Section 5.3. 
Figure 10: Impulse response implications of the Smets-Wouters (2007) model Response to a Price-Markup Shock

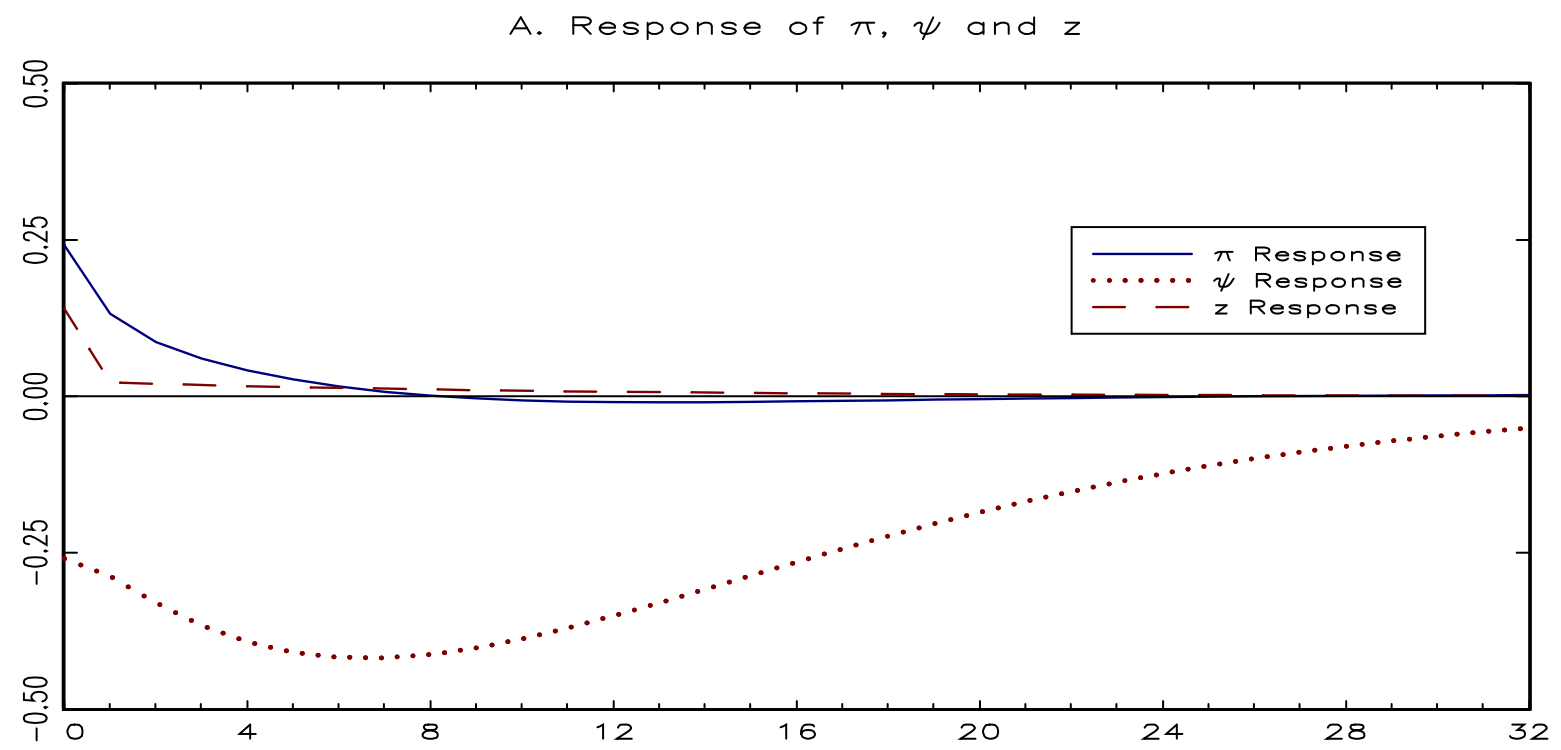

B. Response of $\pi, \pi^{\psi}$ and $\pi^{z}$

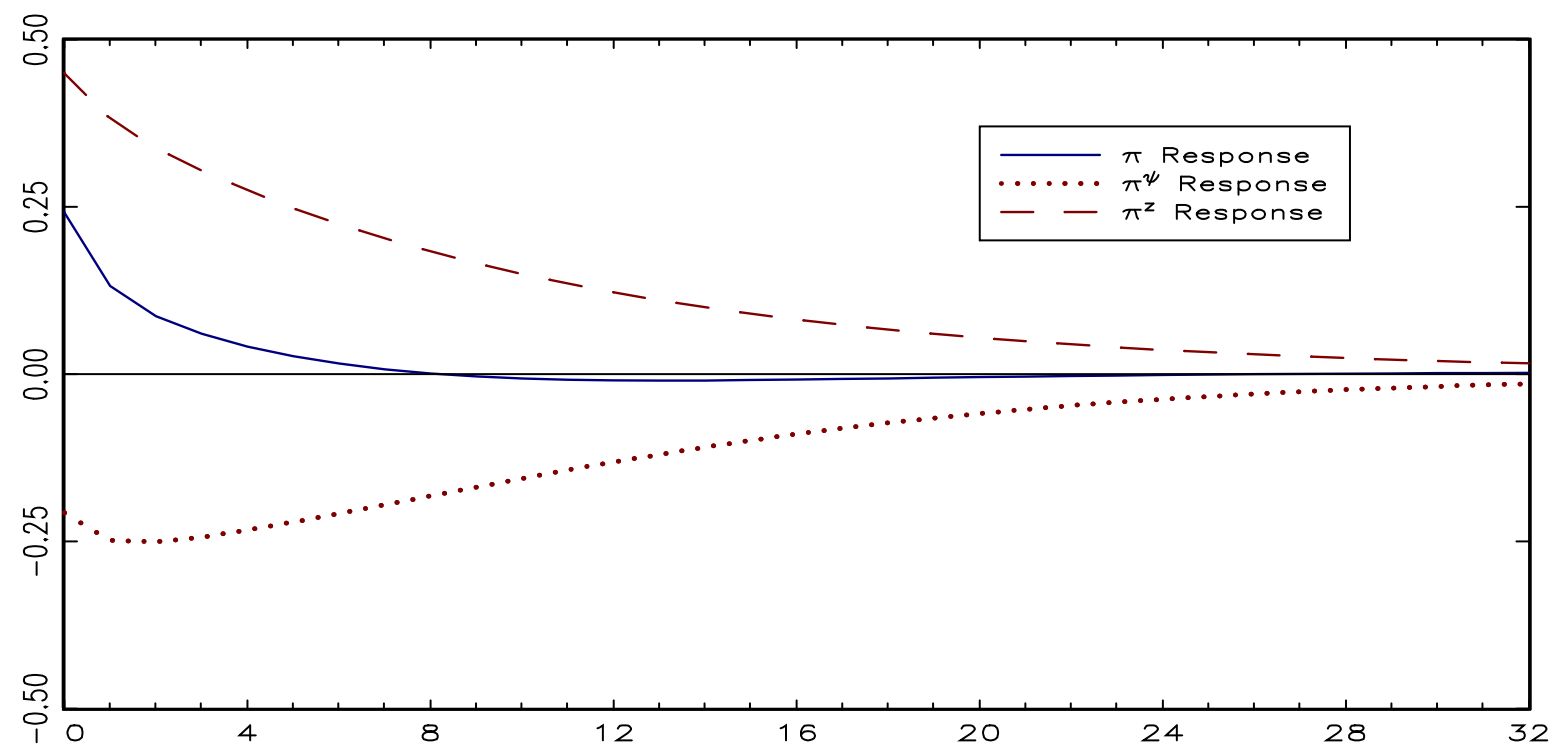

Notes: The panels show the impulse responses from a price-markup shock in the SmetsWouters model computed using the posterior mean of the model's parameters. 
Figure 11: Historical Decomposition of Marginal Cost from Smets-Wouters (2007) model

A. Price Markup Shock
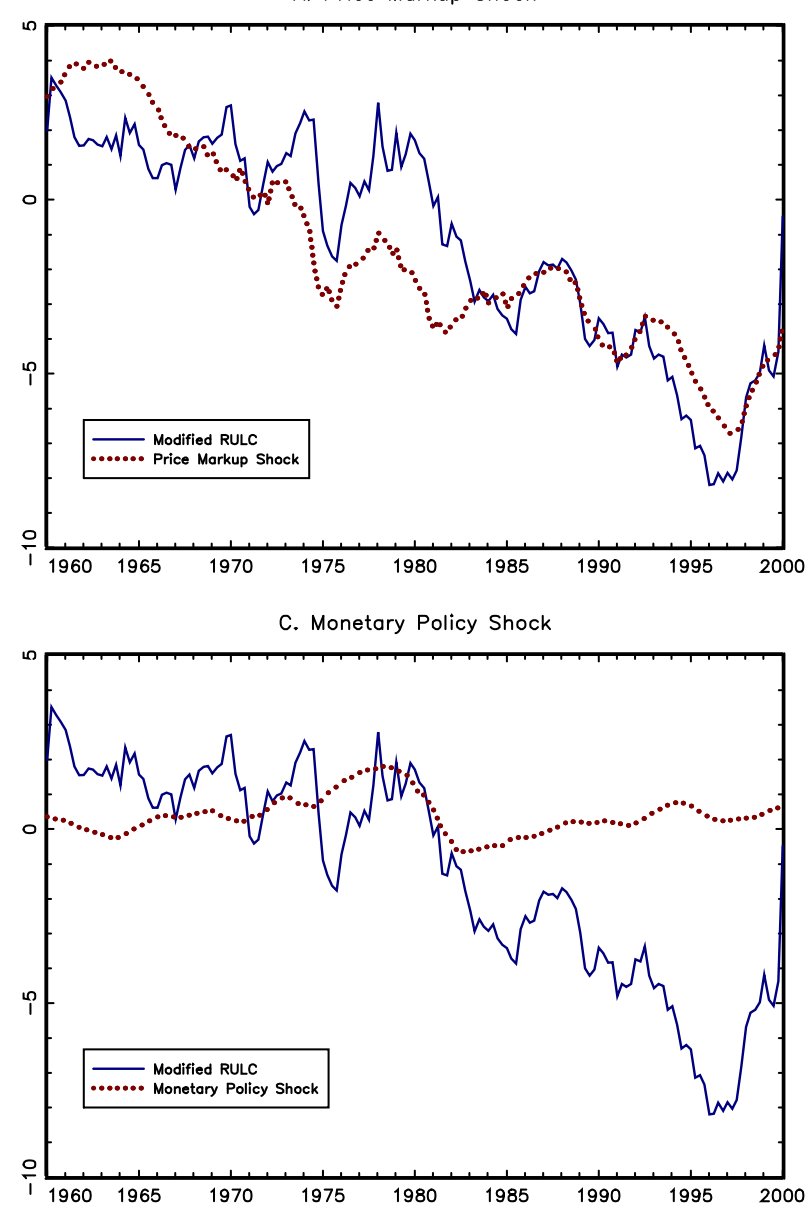

B. Wage Markup Shock
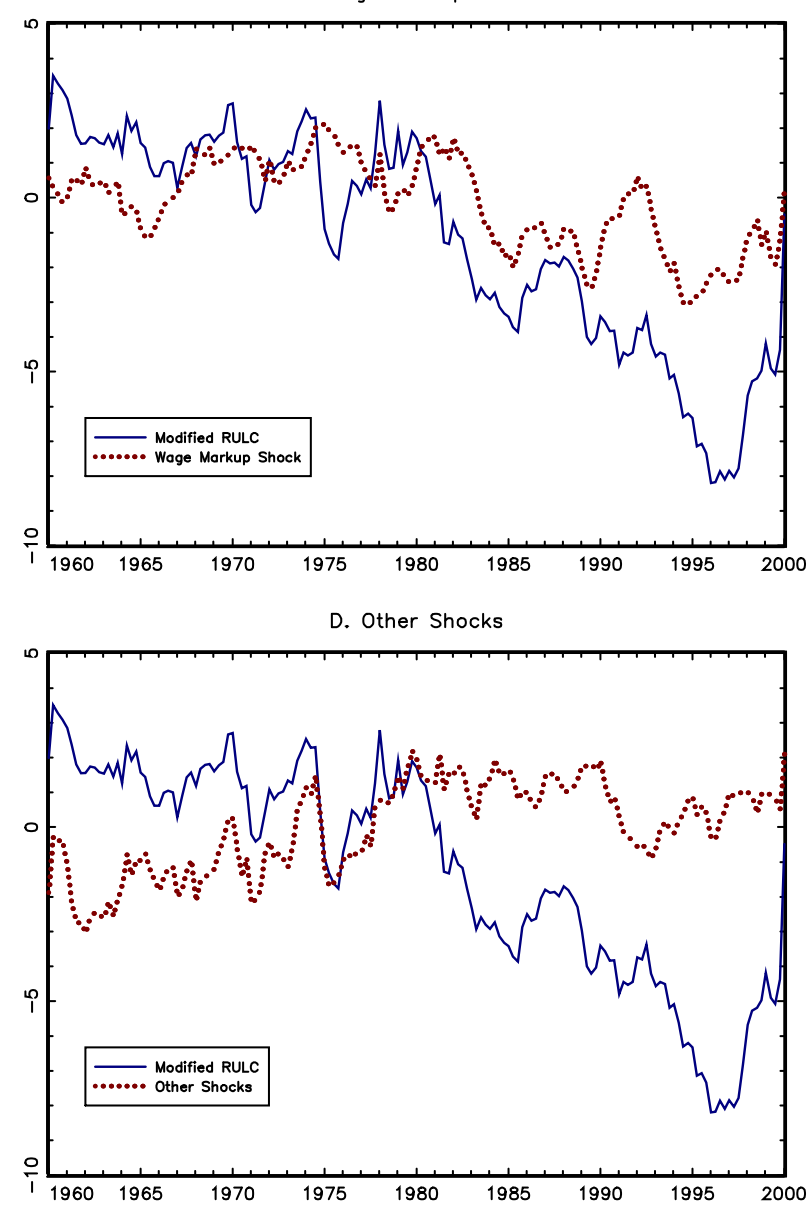

Notes: The solid line is modified real unit labor cost shown in Figure 4, normalized to have a mean of zero over the Smets-Wouters sample period. The dotted lines are the components of cost attributed to (a) price markup shocks; (b) wage markup shocks; (c) monetary policy shocks; and (d) all other shocks, where these shocks and contributions are computed using the DSGE model evaluated at the posterior mean of the model's parameters. 
Figure 12: Two Measures of Real Unit Labor Cost in the Extended Sample

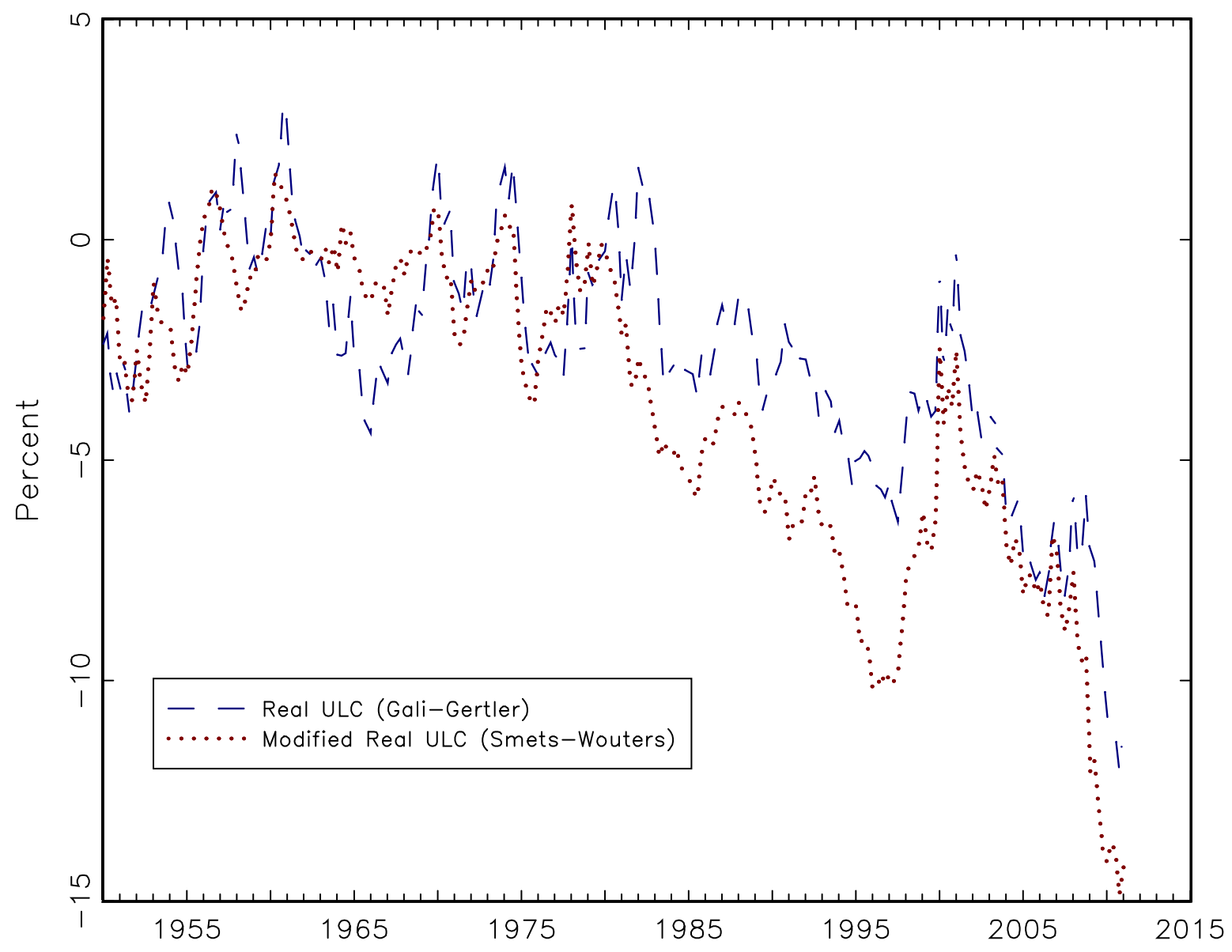

Notes: See notes to Figure 8. 
Figure 13: Actual and Fundamental Inflation Measures in the Extended Sample

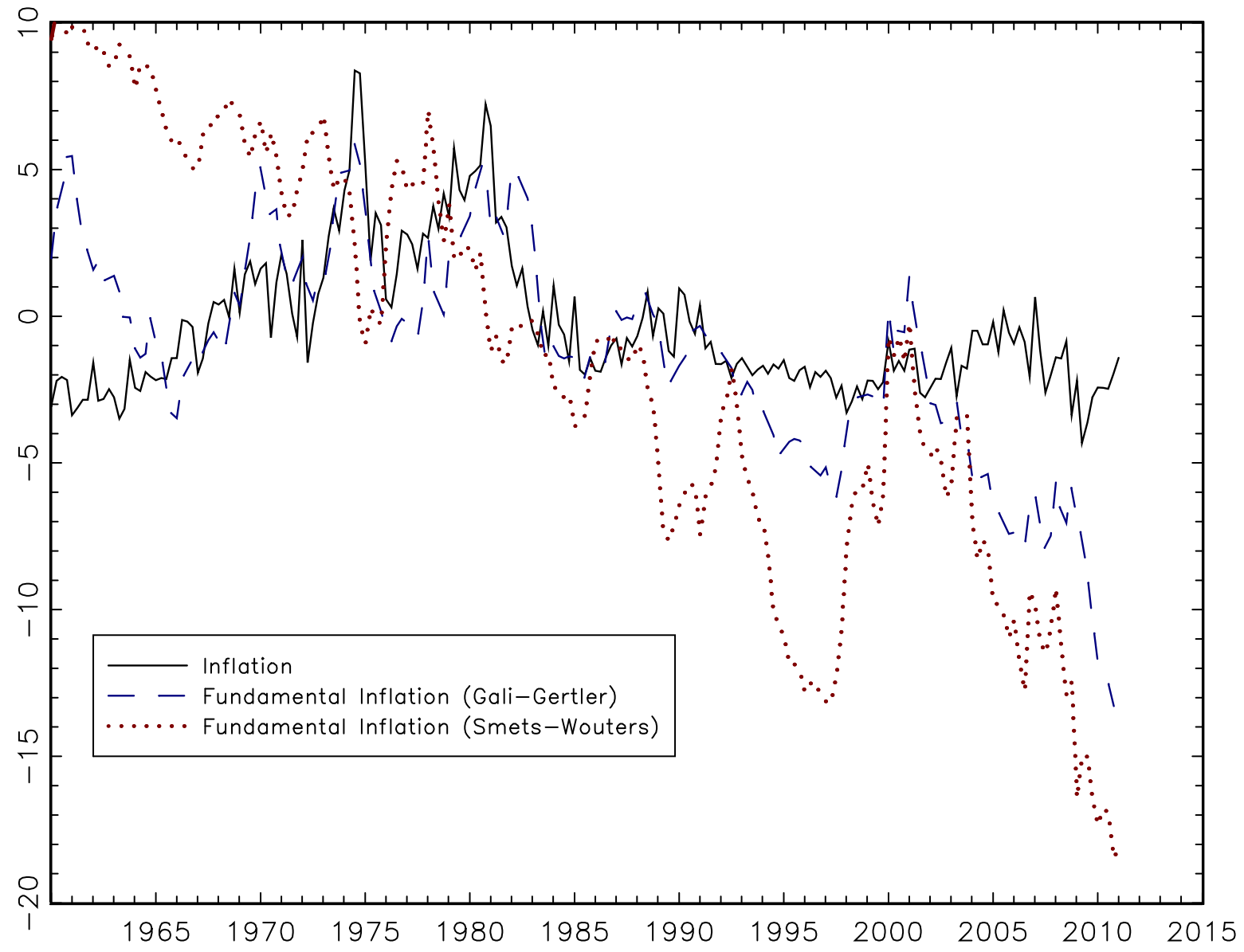

Notes: See notes to Figures 3 and 7. 
Fig 14: Decomposition of Fundamental Inflation in the Smets-Wouters Model

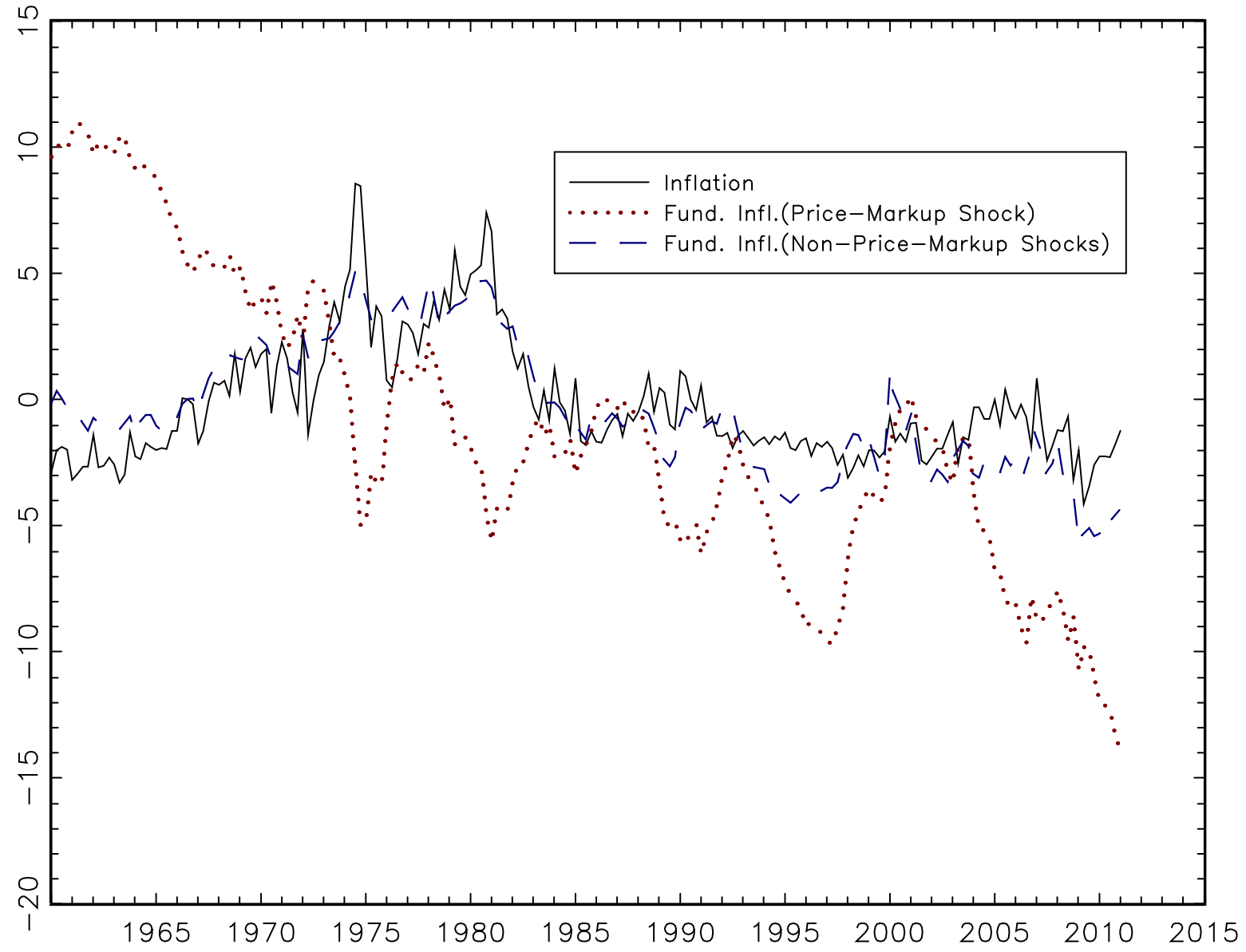

Notes: The solid line is inflation shown in Figure 1. The dotted line is the price-markup component of the SW fundamental inflation. (The values from 1960-1999 are shown in panel (a) of Figure 11.) The dashed line shows the component of the $\mathrm{SW}$ fundamental inflation from shocks other than price-markup shocks. (The values from 1960-1999 are the sum of the components plotted in panels (b)-(d) of Figure 11.) 


\section{Appendix B: Additional Figures}

This appendix shows detrended versions of inflation and unit labor cost measures used by Gali-Gertler and Smets-Wouters. These detrended series were not used in our analysis, but the figures highlight the relationship between the variables absent their low-frequency/trend components.

Figure B.1: Gali and Gertler Data Detrended Inflation and Real Unit Labor Cost

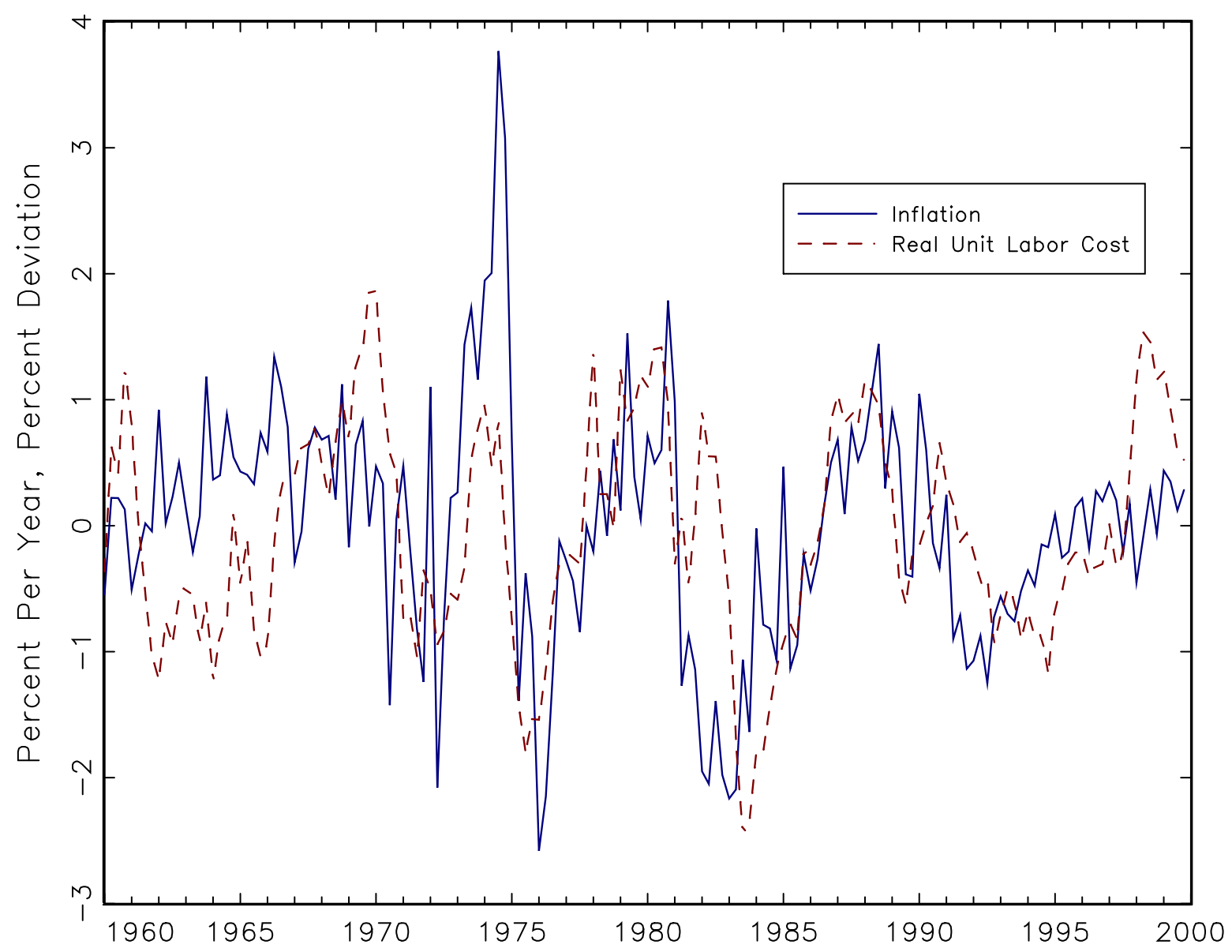

Notes: This figure shows the detrended values of the series plotted in Figure 1. Detrending was carried out using a one-sided high-pass filter with a cutoff of 40 quarters. 
Figure B.2: Smets-Wouters Data

Detrended Inflation and Modified Real Unit Labor Cost

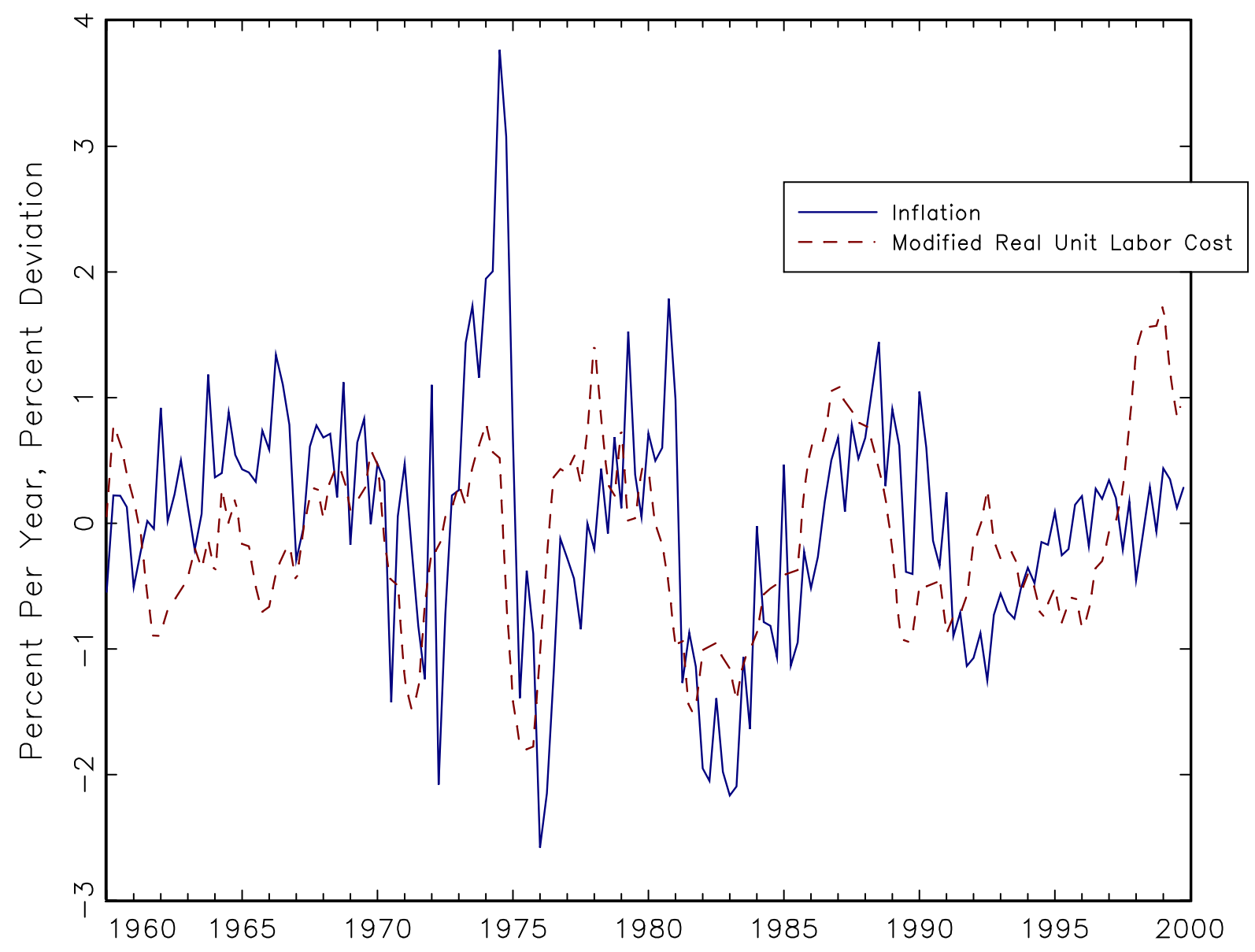

Notes: This figure shows the detrended values of the series plotted in Figure 4. Detrending was carried out using a one-sided high-pass filter with a cutoff of 40 quarters. 
Figure B.3:

Comparison of Gali-Gertler and Smets-Wouters Measures of Real Unit Labor Cost Detrended Data

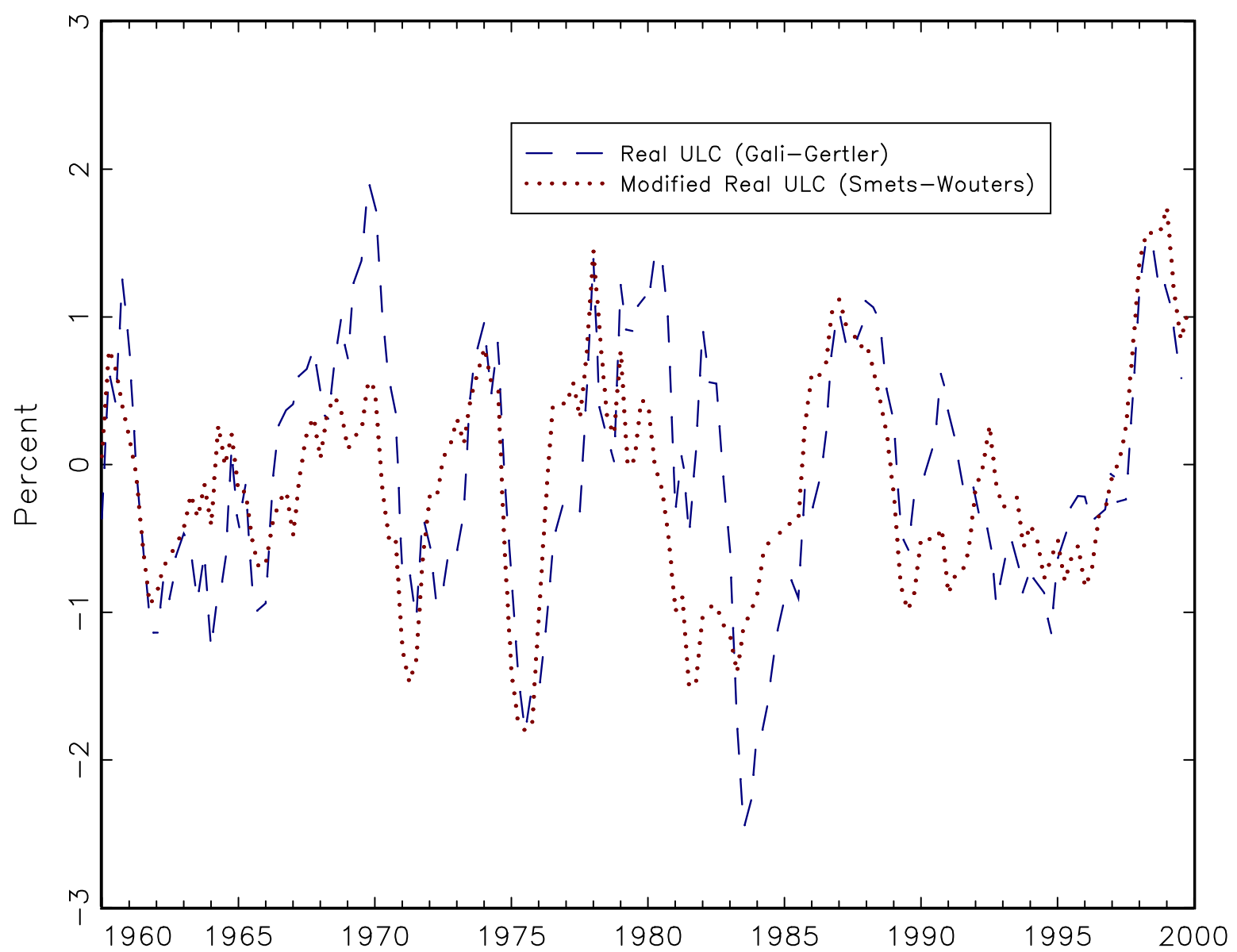

Notes: This figure shows the detrended values of the series plotted in Figure 8. Detrending was carried out using a one-sided high-pass filter with a cutoff of 40 quarters. 